\title{
Review
}

\section{A Nut for Every Bolt: Subunit-Selective Inhibitors of the Immunoproteasome and Their Therapeutic Potential}

\author{
Eva M. Huber *(D) and Michael Groll *iD \\ Chair of Biochemistry, Center for Protein Assemblies, Technical University of Munich, Ernst-Otto-Fischer-Str. 8, \\ 85747 Garching, Germany \\ * Correspondence: eva.huber@tum.de (E.M.H.); michael.groll@tum.de (M.G.)
}

\begin{abstract}
At the heart of the ubiquitin-proteasome system, the $20 \mathrm{~S}$ proteasome core particle (CP) breaks down the majority of intracellular proteins tagged for destruction. Thereby, the CP controls many cellular processes including cell cycle progression and cell signalling. Inhibitors of the CP can suppress these essential biological pathways, resulting in cytotoxicity, an effect that is beneficial for the treatment of certain blood cancer patients. During the last decade, several preclinical studies demonstrated that selective inhibition of the immunoproteasome (iCP), one of several CP variants in mammals, suppresses autoimmune diseases without inducing toxic side effects. These promising findings led to the identification of natural and synthetic iCP inhibitors with distinct chemical structures, varying potency and subunit selectivity. This review presents the most prominent iCP inhibitors with respect to possible scientific and medicinal applications, and discloses recent trends towards pan-immunoproteasome reactive inhibitors that cumulated in phase II clinical trials of the lead compound KZR-616 for chronic inflammations.
\end{abstract}

Keywords: immunoproteasome; inhibition; inflammation; autoimmune diseases; drug development

Citation: Huber, E.M.; Groll, M. A Nut for Every Bolt: Subunit-Selective Inhibitors of the Immunoproteasome and Their Therapeutic Potential. Cells 2021, 10, 1929. https://doi.org/ 10.3390/cells10081929

Academic Editors: Marcus Groettrup and Michael Basler

Received: 21 June 2021

Accepted: 26 July 2021

Published: 29 July 2021

Publisher's Note: MDPI stays neutral with regard to jurisdictional claims in published maps and institutional affiliations.

Copyright: (c) 2021 by the authors. Licensee MDPI, Basel, Switzerland. This article is an open access article distributed under the terms and conditions of the Creative Commons Attribution (CC BY) license (https:// creativecommons.org/licenses/by/ $4.0 /)$.

\section{Introduction}

Protein homeostasis, i.e., balanced protein synthesis and degradation, is essential for cell division and a plethora of intracellular events, among them signal transduction pathways [1,2]. In this regard, protein breakdown has to be tightly controlled and timely regulated. In eukaryotes, proteins destined for degradation are tagged with polyubiquitin chains and targeted to the $26 \mathrm{~S}$ proteasome, a sophisticated molecular machine [3]. Its 19S-cap recognizes and removes the ubiquitin moieties, and, by consuming ATP, unfolds and feeds the polypeptide chains into its proteolytic $20 \mathrm{~S}$ core particle (CP) [4]. The latter subcomplex represents the key component of the ubiquitin-proteasome system and is the target of numerous drugs and natural products $[5,6]$.

The CP is assembled of $14 \alpha$-type and $14 \beta$-type subunits that are stacked in four seven-membered rings around a central pore, creating a barrel [7]. In eukaryotes, the heptameric rings are built of seven distinct $\alpha$ - and and seven distinct $\beta$-subunits following an $\alpha_{1-7} \beta_{1-7} \beta_{1-7} \alpha_{1-7}$ stoichiometry (Figure 1 ) [8]. The $\alpha$-subunits form the entry gates to the catalytic chamber $[9,10]$ and serve as docking sites for the $\beta$-subunits during proteasome assembly [11], as well as for the association with regulatory particles such as the 19S-cap $[12,13]$. Three out of the seven distinct eukaryotic $\beta$-type subunits assembled in a CP, namely $\beta 1, \beta 2$ and $\beta 5$, are proteolytically active [14], and together with their adjacent subunits in the same $\beta$-ring form channels for polypeptide binding [8]. Because the subunits differ in their amino acid composition, these substrate channels vary in their physicochemical properties and give rise to distinct cleavage preferences. Being an endoprotease, each substrate binding channel is composed of primed and non-primed specificity (S) pockets that bind target polypeptides in the C- to N-terminal direction (Figure 2). The primed sites are rather shallow, maybe because they release the C-terminal cleavage product early during the reaction cycle. In contrast, the pronounced non-primed pockets allow 
for tight interactions with the $\mathrm{N}$-terminal polypeptide segment and thereby largely determine cleavage specificity [8]. Between primed and non-primed sites, the scissile peptide bond is cleaved by the active site Thr1 residue (Figure 2), which classifies the proteasome as an N-terminal nucleophile hydrolase. The Thr1 residue is embedded in and activated by two essential hydrogen bond networks [15].

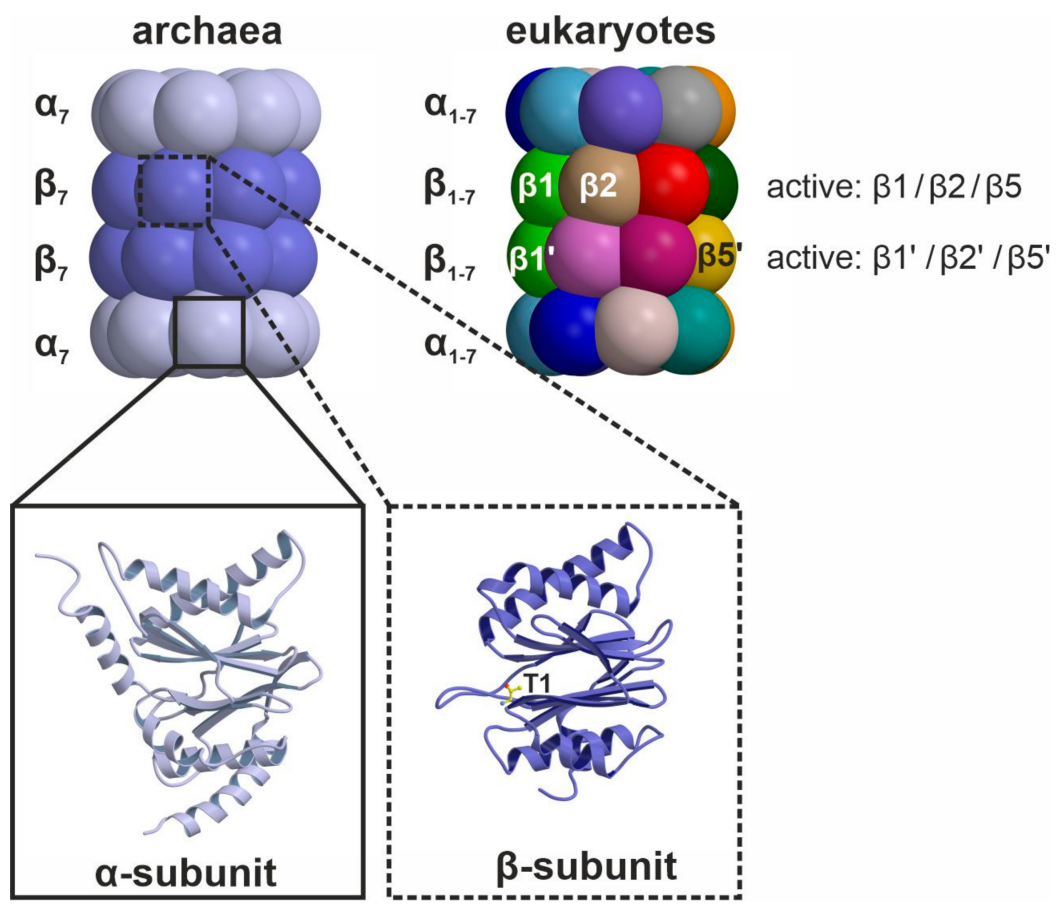

Figure 1. Schematic illustration of archaeal and eukaryotic $20 S$ proteasomes. Simple archaeal $20 S$ proteasome core particles are built of four homo-oligomeric $\alpha$ - and $\beta$-rings. Being identical and harboring a catalytic Thr1 residue, all $\beta$-subunits are proteolytically active. In contrast, eukaryotic CPs bear hetero-oligomeric $\alpha$ - and $\beta$-rings and only three of the seven distinct $\beta$-subunits per ring, namely $\beta 1, \beta 2$ and $\beta 5$, feature an active site. Note that one $\beta 2$ - and one $\beta 5$-subunit are hidden in the back of the particle.

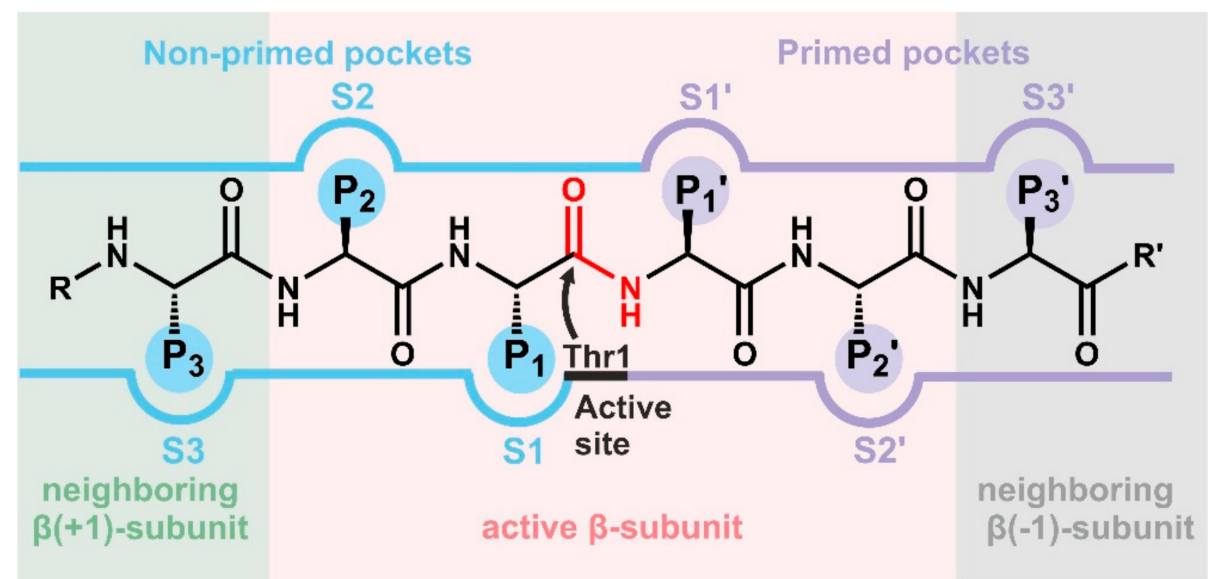

Figure 2. Schematic illustration of the proteasomal substrate binding channel with non-primed (S) and primed $\left(\mathrm{S}^{\prime}\right)$ specificity pockets interacting with the amino acid side chains (P-sites) of a peptide. The proteolytically active $\beta$-subunit features the active site Thr1 and all other catalytic residues, while the neighboring $\beta$-subunits contribute specificity pockets only to the substrate binding channel and do not necessarily feature their own active site. 
In archaea and simple eukaryotes, proteasome activity mainly serves for the production of oligopeptides that are further decomposed into single amino acids by the action of cytosolic peptidases and ultimately reused for de novo protein biosynthesis. In jawed vertebrates like mammals, a fraction of proteasomal cleavage products can escape further degradation by entering the endoplasmic reticulum (ER). After $\mathrm{N}$-terminal trimming by ER-residing peptidases, the fragments associate with major histocompatibility class I (MHC-I) receptors [16]. The resulting complexes are transported to the cell surface and presented to patrolling immune cells [17]. If the immune system detects peptides of foreign, i.e., viral or bacterial, origin on a body cell, the immune defense will be activated and the antigen-presenting cell will be killed to prevent the spreading of the infectious agent $[18,19]$. This process demands for the efficient production and presentation of proteasomal cleavage products and for reliable discrimination of self- and non-self peptides by immune cells. To this end, mammals evolved specialized CP types that shape the adaptive immune system and take over tissue-specific functions in protein degradation [20-22].

Among the four mammalian $\mathrm{CP}$ types, the constitutive proteasome core particle $(\mathrm{cCP})$ is the most abundant, as it is present in all body cells and performs the bulk of intracellular protein degradation. Its subunit composition and cleavage specificities are closely related to the proteasome of unicellular eukaryotes and it comprises the active entities $\beta 1 c, \beta 2 c$ and $\beta 5 c$ [23-26]. The second best characterized $C P$ is the immunoproteasome. Although expression of the immunoproteasome core particle (iCP) can be induced in all body cells by the action of the pro-inflammatory cytokines interferon- $\gamma$ (IFN $\gamma)$ and tumor necrosis factor$\alpha(\mathrm{TNF} \alpha)$, only immune cells constantly produce iCPs [20]. The iCP efficiently generates oligopeptides with hydrophobic C-terminal anchor residues and a high affinity for the MHC-I receptor $[27,28]$, thereby supporting antigen presentation as well as pathogen clearance. This physiological function of the $\mathrm{iCP}$ is based on its altered substrate cleavage preferences emanating from the subunits $\beta 1 \mathrm{i}, \beta 2 \mathrm{i}$ and $\beta 5 \mathrm{i}$ [29-31].

Only in recent years two additional $C P$ types have been discovered; first, the thymoproteasome core particle ( $\mathrm{tCP})$, exclusively present in cortical epithelial cells of the thymus, drives maturation and positive selection of $\mathrm{T}$ cells by producing low affinity peptides for MHC-I receptors [32,33]. This process is crucial for establishing self-tolerance as well as preventing autoimmunity [34] and relies on the unique subunit composition of the tCP ( $\beta 1 \mathrm{i}$, $\beta 2 \mathrm{i}$ and $\beta 5 \mathrm{t}$ ) [32]. The latest discovery of $\mathrm{CPs}$ was the spermatoproteasome (sCP), which is required for proper spermatogenesis in mammalian testes and incorporates a variant of subunit $\alpha 4$, thereby altering the interaction with regulatory particles [35-37]. Apart from these main CP types, a number of mixed particles have been described as well [38-40], however their physiological relevance remains to be investigated in more detail.

In the mid-90s of the last century, scientists started to explore CP inhibition [41]. At that time, it was unknown whether the crucial function of the CP for cell survival would leave a therapeutic window of application for CP inhibitors or not. To date, 30 years later, proteasome inhibition represents an incredible success story that has led to a plenitude of proteasome ligands, both from synthetic and natural sources, including three clinically applied inhibitors (for up-to-date reviews on proteasome inhibition see for example: $[6,42,43]$ ). Bortezomib $\left(\right.$ Velcade $\left.^{\circledR}\right)$, carfilzomib $\left(\right.$ Kyprolis $\left.^{\circledR}\right)$ and ixazomib $\left(\right.$ Ninlaro $\left.^{\circledR}\right)$ significantly improved the clinical outcome of multiple myeloma patients by non-selectively targeting CPs and killing cancer cells that strictly rely on high-capacity protein degradation $[44,45]$. The constant production of antibodies and the accumulation of misfolded immunoglobins sensitize multiple myeloma cells for proteasome inhibition and apoptosis [46]. However, the side effects associated with proteasome inhibition, as well as the high reactivity and cytotoxity of clinically applied compounds, limited additional as well as long-term therapeutic applications in non-malignant diseases so far [47,48]. During the last decade, with increasing knowledge about the iCP, selective inhibition of $\mathrm{CP}$ subtypes and single subunits was explored. Initial preclinical studies reported impressive results, suggesting that selective inhibition of the iCP could be beneficial for the treatment of autoimmune diseases, for which only few modestly effective therapeutic 
options are currently available. The intimate connection between the iCP and pathogenesis of inflammatory diseases or certain cancers opened up a new field of proteasome research and this review intends to cover the developments in this vivid area of academic and pharmaceutical research.

\section{Principles of Proteasome Inhibition}

\subsection{Covalent Versus Non-Covalent Inhibitors}

Inhibitors can be grouped into non-covalently and covalently acting ones depending on their type of interaction with the target protein. The former group acts per se reversibly, while covalent inhibitors can form permanent (irreversible) or transient (reversible) linkages with proteins. In general, non-covalent inhibitors are expected to cause less unwanted side effects and to have fewer off-targets. Moreover, they are rumored to be less toxic and target single subunits more selectively than their covalent counterparts, the selectivity of which may be obscured by off-target modifications after long-term exposure. Although non-covalently acting CP inhibitors have been investigated in detail (reviewed for example in $[49,50])$, none of them have been investigated in clinical trials so far. Most importantly, the high substrate turnover of CPs and the accumulation of substrates upon CP inhibition may interfere with tight and sustainable blockage, thus leading to early displacement of inhibitors from the active sites without inducing significant and therapeutically relevant effects [51]. Despite their high and often indiscriminate reactivity associated with off-target activities, covalent inhibitors are currently experiencing a revival in drug development [52] and appear to be the compounds of choice for CP inhibitors with clinical applications. Their advantages are high potency, lower effective doses, long-lasting effects by low dissociation rates or irreversible inhibition, favorable pharmacodynamic profiles (that endure detectable drug levels in body fluids), and less sensitivity to pharmacokinetics (e.g., resorption and metabolism) [53]. Although there are exceptions (see Sections 4.1.1, 4.3.1 and 5.1), most proteasome inhibitors share a peptidic scaffold with a C-terminal electrophilic warhead that covalently targets the catalytic Thr1 residue (see also Section 2.2). Among the class of non-covalent CP inhibitors, non-peptidic ones are also known, which offer superiority in terms of metabolic stability and bioavailability. Of note, most natural and synthetic $\mathrm{CP}$ ligands target the non-primed substrate binding pockets that are more pronounced compared to their primed counterparts. In the following sections, inhibitors with all kinds of structures, functional groups and iCP subunit profiles will be presented and discussed in the context of their therapeutic potential.

\subsection{Important Reactive Warheads}

Various electrophilic head groups can covalently target the CP, including aldehydes, vinyl sulfones, vinyl amides, $\beta$-lactones, boronic acids and $\alpha, \beta$-epoxyketones, among others. Their reaction mechanisms, as well as pros and cons, are discussed in detail elsewhere, for example in $[5,49,54]$. Here, only boronic acids and $\alpha, \beta$-epoxyketones are introduced, as these are the electrophiles most frequently used for iCP inhibitor development.

Boronates are a group of highly reactive, slowly reversible $\mathrm{CP}$ inhibitors. In this regard, a number of off-targets have been reported for bortezomib, the prototype boronic acid CP inhibitor and frontline treatment for multiple myeloma patients. In particular, co-inhibition of neuronal serine proteases by bortezomib has been correlated with severe neurodegeneration and neurotoxicity [55]. Although this off-target activity can be reduced as exemplified with ixazomib [56], oxidative deboronation and subsequent reaction with, for example, glutathione, might also cause unwanted effects $[57,58]$.

With the discovery of the natural product epoxomicin and its electrophilic epoxyketone warhead, an alternative to aldehydes and boronic acids became available [59]. Modifying both the Thr1 hydroxyl group and its free N-terminus [60], the epoxyketone irreversibly inhibits proteasome activity without touching other intracellular serine or cysteine proteases [55]. This improvement in selectivity led to the approval of the second-generation CP inhibitor carfilzomib (Kyprolis $®$ ) for clinical use [61]. The epoxyketone warhead was 
also selected for the development of various peptide-based iCP selective inhibitors (see Sections 4.3.2 and 5.4-5.6).

\section{Inhibition of the Immunoproteasome-A Short Historic Outline}

Along with the growing clinical success of the broad-spectrum proteasome inhibitor bortezomib (Velcade $₫$ ) in the early 2000s [62] and the discovery of CP subtypes, the interest in selective CP inhibition rose. In 2009, the report of the iCP ligand ONX 0914 (formerly PR-957) and evidence for its therapeutic activity in mouse models of autoimmune disorders caused sensation [63]. The study provided the proof-of-concept for selective iCP inhibition and opened up new fields of application-in particular for diseases that are characterized by elevated iCP levels, such as chronic inflammatory syndromes, certain types of cancers and neurodegenerative diseases. Inspired by the hope for lower effective doses, less side effects and better safety profiles compared to conventional non-selective CP inhibitors, the development of and screening for subtype-selective $\mathrm{CP}$ ligands by academic groups and pharmaceutical companies soon picked up speed. In parallel, structural studies on the iCP were conducted to facilitate and support drug design [26,64-66]. This combined effort over the last decade led to the identification of numerous inhibitors for all active sites of cCP and iCP. Besides serving as excellent research tools to monitor proteasome activities [67] and to assess the contribution of single $\mathrm{CP}$ subunits to antigen processing, presentation [68] and cytokine production, these compounds allowed further exploration of the role of the $\mathrm{iCP}$ in disease progression and potential therapeutic applications [47]. Their respective chemical structures, their development, as well as their biological activities are thoroughly discussed in Section 4. However, as the therapeutic benefit of single-subunit-selective inhibition in preclinical models of autoimmune diseases turned out to be low, co-inhibition of at least two iCP subunits was aspired. In this regard, ONX 0914, initially considered as $\beta 5 \mathrm{i}-$ selective, has recently been re-classified as a pan-iCP inhibitor that targets both $\beta 5 \mathrm{i}-$ and $\beta 1$ i-subunits [69]. Section 5 will account for the current developments in the field of pan-immunoproteasome inhibition and highlight promising compounds that might find clinical applications in the future.

\section{Subunit-Selective Inhibitors of the Immunoproteasome}

4.1. Inhibitors of Subunit $\beta 1 i$

Already in the 1990s it was noted that iCP and cCP differ in their substrate cleavage preferences. For iCPs, cleavages after acidic residues (caspase-like activity) were found to be reduced, whereas hydrolysis after hydrophobic (chymotrypsin-like (ChT-L) activity) and basic (trypsin-like activity) residues was enhanced [29,70]. This notion correlated with structure-based comparison of $\beta 1 c-$ and $\beta 1$ i-sequences [8], indicating that key polar residues in the substrate binding channel of subunit $\beta 1 \mathrm{c}$ in $\mathrm{CCPs}$ are replaced by hydrophobic ones in $\beta 1 \mathrm{i}$ of iCPs. These findings allowed for the development of $\beta 1$ i-selective inhibitors long before structural data visualized the $\beta 1 \mathrm{i}$-substrate binding channel for the first time [26].

\subsubsection{Non-Covalent Inhibitors}

The only known non-covalent inhibitor with pronounced $\beta 1$ i-selectivity has been reported by Ettari et al.; amide compound 7 has a $K_{i}$ value of $0.021 \mu \mathrm{M}$ for $\beta 1 \mathrm{i}$ and retains a residual activity for other $\mathrm{CCP}$ and iCP subunits of $>17 \%$ at $50 \mu \mathrm{M}$ (Table 1; Figure 3) [71]. Molecular docking indicates smooth fitting to the $\beta 1 \mathrm{i} / \beta 2 \mathrm{i}$-substrate binding channel similar to ONX 0914 [71], thus qualifying the compound as a suitable building block for future fragment-based drug design strategies. 
Table 1. Overview of iCP selective inhibitors and their potency. Due to space limitations, only key compounds of each class are presented. $\mathrm{IC}_{50}$ values (given in $[\mu \mathrm{M}]$ ) depend on the chosen setting (purified $\mathrm{CP} /$ cell lysate/in cells), enzyme concentration and time of incubation, and thus are hardly comparable. As a measure of subunit selectivity, ratios of $\mathrm{IC}_{50}$ values are given. The ratio positively correlates with selectivity for the respective i-subunit. 'n.r.' designates values that have not been reported. Colors reflect the distinct selectivity patterns of inhibitors: green for $\beta 1 i^{-}$, brown for $\beta 2 i-$, yellow for $\beta 5 \mathrm{i}$ - and gray for pan-reactive inhibitors. Inhibition values are light-colored, while selectivity ratios are dark-shaded. Most pan-reactive inhibitors target $\beta 1 \mathrm{i}$ and $\beta 5 \mathrm{i}$ (green and yellow shades, respectively). Only LU-005i moderately inhibits all immunoproteasome subunits (green, brown and yellow shades).

\begin{tabular}{|c|c|c|c|c|c|c|c|c|c|c|c|c|}
\hline - & Compound & Source & $\beta 1 \mathrm{i}$ & $\beta 1 c$ & $\beta 1 c / \beta 1 i$ & $\beta 2 \mathrm{i}$ & $\beta 2 \mathrm{c}$ & $\beta 2 \mathrm{c} / \beta 2 \mathrm{i}$ & $\beta 5 i$ & $\beta 5 c$ & $\beta 5 c / \beta 5 i$ & Reference \\
\hline & 7 & Academia & $0.021^{2}$ & n.r. & n.r. & n.r. & n.r. & n.r. & n.r. & n.r. & n.r. & [71] \\
\hline है & ML604440 & Mill. Pharm. & $\sim 0.0125$ & n.r. & n.r. & n.r. & n.r. & n.r. & $>1$ & $>1$ & 1 & [72] \\
\hline 氖 & UK-101 & Academia & 0.104 & 15 & 144 & 17 & 25 & 1.4 & 3.1 & 1 & 0.3 & {$[73,74]^{1}$} \\
\hline फँّ & LU-001i & Academia & 0.095 & 24 & 252 & $>100$ & $>100$ & 1 & 20 & 20 & 1 & [73] \\
\hline$\Rightarrow$ & DB-310 & Academia & 0.070 & 0.590 & 8 & n.r. & n.r. & n.r. & $>10$ & $>10$ & 1 & [75] \\
\hline & KZR-504 & Kezar L. Sci. & 0.051 & 46.35 & 908 & $>250$ & $>250$ & 1 & 4.3 & 6.9 & 1.6 & [76] \\
\hline $\begin{array}{c}\beta 2 \mathrm{i}- \\
\text { selective }\end{array}$ & LU-002i & Academia & $>100$ & $>100$ & 1 & 0.18 & 12.1 & 67 & $>100$ & $>100$ & 1 & [77] \\
\hline \multirow{15}{*}{ 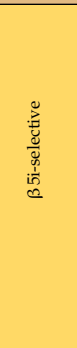 } & 1 & Academia & n.r. & n.r. & n.r. & n.r. & n.r. & n.r. & 1.7 & $>5$ & $>2$ & {$[78]$} \\
\hline & 3 & Academia & $>100$ & $>100$ & 1 & $\sim 100$ & $<100$ & n.r. & $1.6^{2}$ & $172.2^{2}$ & 107 & [79] \\
\hline & DPLG3 & Academia & $>33.3$ & $>33.3$ & 1 & $>33.3$ & $>33.3$ & 1 & 0.0045 & 32.4 & 7200 & [80] \\
\hline & Ro19 & Roche & 20 & 20 & 1 & $20^{3}$ & n.r. & n.r. & 0.025 & 20 & 800 & [81] \\
\hline & PRN1126 & $\begin{array}{l}\text { Princ. } \\
\text { Bioph. }\end{array}$ & $>10$ & $>10$ & 1 & $>10$ & $>10$ & 1 & 0.0072 & 0.21 & 29 & [69] \\
\hline & 16 & Merck & n.r. & n.r. & n.r. & n.r. & n.r. & n.r. & $<0.05$ & $>5$ & $\geq 150$ & [82] \\
\hline & 4-CA & Academia & $>100$ & $>100$ & 1 & $>100$ & $>100$ & 1 & 0.64 & $>100$ & $>156$ & [83] \\
\hline & HT2004 & Academia & n.r. & n.r. & n.r. & n.r. & n.r. & n.r. & $1093^{4}$ & $0.23^{4}$ & 47524,7 & [48] \\
\hline & Piperlongumine & Academia & n.r. & $>50$ & n.r. & n.r. & n.r. & n.r. & 15 & $>50$ & $>3.3$ & [84] \\
\hline & $1 \mathrm{a}$ & Academia & n.r. & n.r. & n.r. & n.r. & n.r. & n.r. & 34 & 102 & 3 & [85] \\
\hline & 22 & Genentech & 8.5 & $>20$ & $>2$ & n.r. & n.r. & n.r. & 0.0041 & 9.1 & 2219 & [65] \\
\hline & M3258 & Merck & $>30$ & $>30$ & 1 & $>30$ & $>30$ & 1 & 0.0041 & 2.519 & 614 & [66] \\
\hline & PR-924 & Proteolix & 8.2 & $>30$ & $>3$ & $>30$ & $>30$ & 1 & 0.022 & 2.9 & 131 & [86] \\
\hline & LU-035i & Academia & $>10$ & $>10$ & 1 & $>10$ & $>10$ & 1 & 0.011 & 5.5 & 500 & [73] \\
\hline & 8 & Kezar L. Sci. & 1.85 & $>25$ & $>13$ & $>25$ & $>25$ & 1 & 0.034 & 2.67 & 78 & [87] \\
\hline \multirow{6}{*}{ 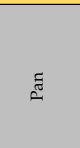 } & 6 & Academia & $4.9^{2}$ & n.r. & n.r. & $>100$ & n.r. & n.r. & $4.4^{2}$ & n.r. & n.r. & [88] \\
\hline & IPSI-001 & Academia & $1.45^{2}$ & $239^{2}$ & 164 & n.r. & n.r. & n.r. & $1.03^{2}$ & $105^{2}$ & 101 & [89] \\
\hline & $1 \mathrm{~b}$ & Roche & 0.004 & 0.32 & 80 & $20^{3}$ & n.r. & n.r. & 0.002 & 0.039 & 19 & {$[90]$} \\
\hline & LU-005i & Academia & 0.052 & $>1$ & $>19$ & 0.47 & 3.1 & 6 & 0.16 & 3 & 18 & {$[73,91]^{5}$} \\
\hline & ONX 0914 & Onyx Phar. & 0.46 & $>10$ & $>21$ & 0.59 & 1.1 & 1.8 & 0.0057 & 0.054 & 9 & {$[63,73]^{6}$} \\
\hline & KZR-616 & Kezar L. Sci. & 0.131 & $>10.6$ & $>80$ & 0.623 & 0.604 & 1 & 0.039 & 0.688 & 17 & {$[87]$} \\
\hline
\end{tabular}

${ }^{1} \mathrm{IC}_{50}$ values were derived from the first reference; the second reference reports the inhibitor. ${ }^{2} \mathrm{~K}_{\mathrm{i}}$ values instead of $\mathrm{IC}_{50}$ values. ${ }^{3}$ No differentiation between $\beta 2 \mathrm{c}$ and $\beta 2 \mathrm{i}$ was made. ${ }^{4} \mathrm{~K}_{\text {inact }} / \mathrm{K}_{\mathrm{i}}$ values instead of $\mathrm{IC}_{50}$ values. In contrast to $\mathrm{IC}_{50}$ values, high $\mathrm{K}_{\text {inact }} / \mathrm{K}_{\mathrm{i}}$ values correspond to high potency. ${ }^{5}$ The first reference reports the inhibitor, but inhibition values were derived from the second reference. ${ }^{6}$ The first reference reports the inhibitor but no numerical $\mathrm{IC}_{50}$ values for all active sites. Therefore, $\mathrm{IC}_{50}$ values were derived from the second reference. ${ }^{7}$ The 4752 -fold selectivity for $\beta 5 \mathrm{i}$ corresponds to the ratio of $\beta 5 \mathrm{i} / \beta 5 \mathrm{c} \mathrm{K}_{\text {inact }} / \mathrm{K}_{\mathrm{i}}$ values.

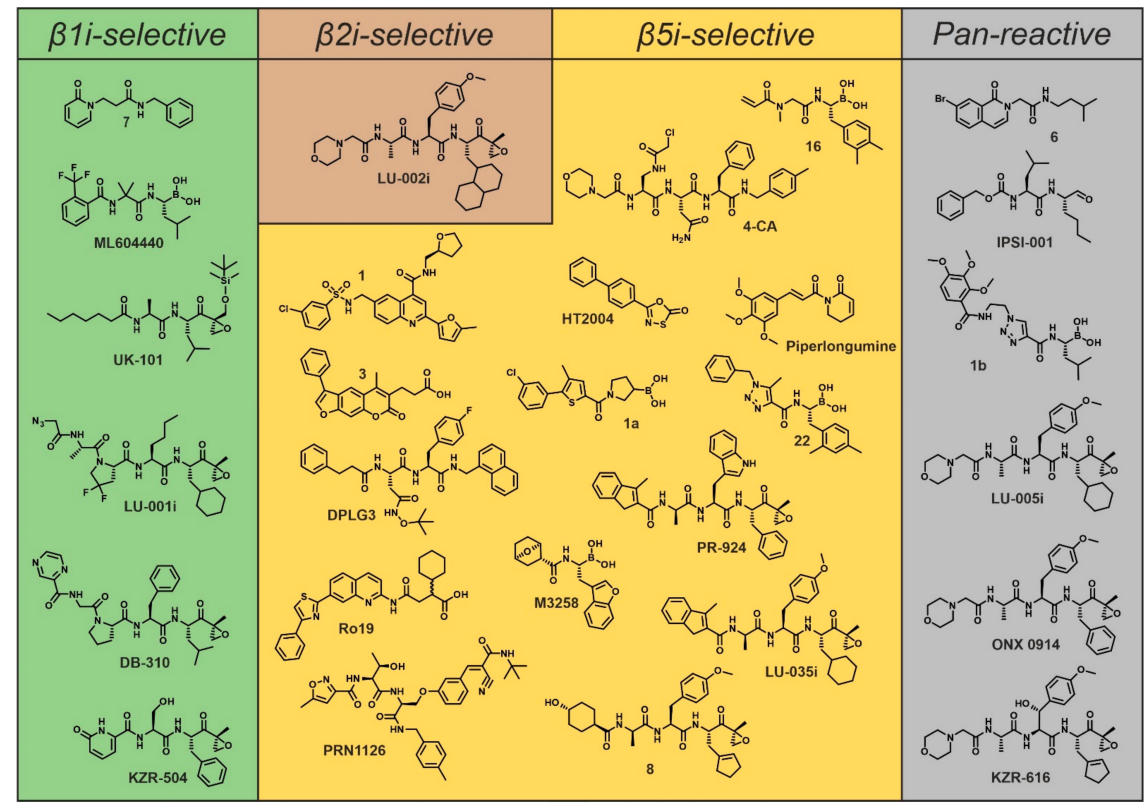

Figure 3. Chemical structures of non-covalently and covalently acting iCP inhibitors. Compounds are grouped and colored according to their subunit selectivity and arranged according to their discussion in the text. The original compound numbering from patents or publications was taken over wherever possible (for references see Table 1). To avoid duplicates, compounds $1 \mathrm{a}$ and $1 \mathrm{~b}$ were given a letter in addition. For inhibition values see Table 1 . Due to space limitations, only selected compounds of each class are depicted. 


\subsubsection{Covalent Inhibitors}

In 2007, Millenium Pharmaceuticals Inc. filed a patent on peptide boronic acid inhibitors, among them a fluorinated $\beta 1$ i-selective derivative of bortezomib, termed ML604440 (Figure 3) [92]. Later, this dipeptide boronate was used to study differential antigen processing by the subunits $\beta 1 \mathrm{c}$ and $\beta 1 \mathrm{i}[72]$ and to evaluate therapeutic effects on immune thrombocytopenia, an autoimmune bleeding disorder. Peripheral blood mononuclear cells of patients suffering from immune thrombocytopenia showed increased expression of $\beta 1 \mathrm{i}$, but treatment with ML604440 failed to normalize the number of platelets in mice with immune thrombocytopenia [93]. In contrast, ONX 0914 was able to revert platelet counts in this mouse model, suggesting that selective inhibition of $\beta 1 \mathrm{i}$ may not be sufficient to reach therapeutic efficacy [93].

In 2009, UK-101, a structural derivative of dihydroeponemycin, was reported to be a $\beta 1$ i-selective inhibitor [74]. Its aliphatic $n$-heptanoic tail is directed to the interface of $\beta 1 \mathrm{i}-$ and $\beta 2 \mathrm{i}$-subunits and the tert-butyldimethylsilyl group hinders modification of $\beta 5$ subunits (Figure 3) $[94,95]$. UK-101 targets subunit $\beta 1 \mathrm{i}$ in Raji cell lysates with an IC 50 value of $0.104 \mu \mathrm{M}$, and shows 144-fold selectivity over $\beta 1 \mathrm{c}$ (Table 1), and 10- and 30-fold selectivity over $\beta 5 \mathrm{c}$ as well as $\beta 5 \mathrm{i}$, respectively. This modest subunit selectivity profile resembles that of the parent molecule dihydroeponemycin [94,96]. UK-101 has been shown to inhibit proliferation of prostate cancer cells $[74,97]$ and tumor growth in a xenograft mouse model of prostate cancer [97], but this effect may result from partial co-inhibition of $\beta 5 \mathrm{i}-$ and $\beta 5 \mathrm{c}$-active sites at the applied concentrations [73,75]. In agreement, off-target activities towards other proteasome subunits have been observed over time and these may result from cleavage of the ether bond by an intracellular hydrolase and loss of the tert-butyldimethylsilyl group, resulting in progressive co-inhibition of $\beta 5$-active sites [98].

Based on NC-001, a potent $\beta 1$-inhibitor [99], the Overkleeft group developed a $\beta 1 \mathrm{i}$ selective epoxyketone. The tetrapeptide LU-001i features a fluorinated L-Pro analogue at P3 (Figure 3) and has similar potency to UK-101 but higher subunit selectivity. IC 50 values were determined in Raji cell lysates as $0.095 \mu \mathrm{M}$ for $\beta 1 \mathrm{i}$ and $24 \mu \mathrm{M}$ for $\beta 1 \mathrm{c}$ (252-fold selectivity for $\beta 1 \mathrm{i}$ over $\beta 1 \mathrm{c}$ ), and $\geq 20 \mu \mathrm{M}$ for all other proteasome subunits (Table 1) [73]. Being active in cells, the therapeutic potential of LU-001i was evaluated in vitro and in vivo. These studies revealed that LU-001i alone is unable to block differentiation of T helper cells or lower MHC-I surface and cytokine expression [91]. Most importantly however, it lacks the potential to ameliorate symptoms of dextran sulfate sodium-induced colitis in mice [91].

Recently, another epoxyketone, dubbed DB-310, has been reported to be a potent and selective $\beta 1$ i-inhibitor (Figure 3 ). It is claimed to have improved selectivity and permeability in cells that overexpress the efflux transporter ABCB1-a requirement for brain barrier penetration. With its moderate $\beta 1$ i-selectivity ( $\sim$-fold), DB-310 suppresses proinflammatory cytokines and leads to cognitive improvements in a mouse model of Alzheimer's disease [75].

The most potent and selective $\beta 1$ i-inhibitor known to date, KZR-504, has been described by Kezar Life Sciences Inc. (Figure 3). IC 50 values were determined in MOLT-4 (human T cell leukemia) cell lysates as $0.051 \mu \mathrm{M}$ for $\beta 1 \mathrm{i}$ and $46.35 \mu \mathrm{M}$ for $\beta 1 \mathrm{c}$ (908-fold selectivity for $\beta 1$ i over $\beta 1 c$; Table 1) [76]. Although KZR-504 has been improved with respect to solubility and stability, it failed to suppress the production of pro-inflammatory cytokines in in vitro cell culture assays [76], similar to LU-001i [91].

Given the shallow S2-pockets of proteasome substrate binding channels [26], the presented $\beta 1$ i-selective ligands are diverse in their P2-sites but share some structural features at their P1- and P3-sites. First, Leu (UK-101, DB-310 and ML604440), cyclohexyl (LU-001i) and Phe (KZR-504) moieties are reasonable P1-sites to target $\beta 1$ i. Second, most $\beta 1$ i-selective compounds share a cyclic residue at $\mathrm{P} 3$ - a structural feature that is also known from the peptide substrate Ac-PAL-AMC, used to selectively monitor $\beta 1$ i-activity by fluorescence spectroscopy [100]. Like Ac-PAL-AMC, LU-001i and DB-310 carry a P3-L-Pro residue, while KZR-504 and ML604440 feature a 2-pyridone or a 2-trifluoromethylbenzoyl moiety, 
respectively. Although cyclic residues appeared to drive $\beta 1$-selectivity in general [73,76], the reason for this observation was initially unclear. In 2015, a structural study showed that compounds with Pro at P3 are tilted in $\beta 2 / \beta 3$ - and $\beta 5 / \beta 6$-substrate binding channels compared with their Leu analogues. However, no such effect has been observed at the $\beta 1 / \beta 2$-active sites. Particularly, Asp114 of $\beta 3$ and $\beta 6$ as part of the $\beta 2 / \beta 3$ - and $\beta 5 / \beta 6$-substrate binding channels displaces P3-Pro ligands and leads to their pronounced $\beta 1$-selectivity [101]. Similar findings were recently reported by Johnson et al., who showed by molecular modelling that the 2-pyridone moiety of KZR-504 fails to interact with Asp114 of $\beta 3$ - and $\beta 6$-subunits [76].

\subsection{Covalent Inhibitors of Subunit $\beta 2 i$}

Historically, subunit $\beta 2 \mathrm{c}$ of $\mathrm{cCPs}$ has been assigned trypsin-like activity, but in fact it is rather promiscuous, because its S1-pocket, the major determinant of substrate specificity, is lined with Gly 45 and thus is rather spacious [8]. Subunit $\beta 2 \mathrm{i}$ of iCPs is highly similar to its constitutive counterpart $\beta 2 \mathrm{c}$ in terms of structure and activity [26], raising questions about the biological function and benefit of $\beta 2 \mathrm{i}$ versus $\beta 2 \mathrm{c}$. Additionally, the structural similarity precludes development of subunit-selective fluorogenic substrates [100] and inhibitors.

Nonetheless, after huge screening efforts, some progress in this field was recently reported. Synthesis and evaluation of a library of ONX 0914 derivatives identified the $\beta 2 i$-selective compound LU-002i (Figure 3) [77]. ONX 0914 served as a blueprint, as it slightly discriminates between $\beta 2 \mathrm{i}$ and $\beta 2 \mathrm{c}(\sim 1.8$ fold preference for $\beta 2 \mathrm{i})$ according to its subunit selectivity profile [73]. By installing large P1-sites on the otherwise unchanged ONX 0914 scaffold, LU-002i with pronounced $\beta 2 \mathrm{i}$-selectivity and potency was obtained $\left(\mathrm{IC}_{50}\right.$ values determined in Raji cell lysates: $0.18 \mu \mathrm{M}$ for $\beta 2 \mathrm{i} ; 12.1 \mu \mathrm{M}$ for $\beta 2 \mathrm{c} ; \beta 2 \mathrm{c} / \beta 2 \mathrm{i}$ ratio: 67; Table 1). To visualize the structural basis for this selectivity of LU-002i, yeast proteasomes having incorporated large parts of human $\beta 2 c$ - or $\beta 2 \mathrm{i}$-subunits were designed and produced [77]. Complex structures with a derivative of LU-002i revealed that the $\beta 2 \mathrm{i}$-active site can adapt more easily to bulky P1-residues, whereas the corresponding site in $\beta 2 c$ seems to be rather rigid. In particular, the hydrogen bond interaction between Asp53 and His35 in $\beta 2 \mathrm{c}$ might oppose the binding of inhibitors staffed with large P1-sites, while Glu53 of $\beta 2$ i might allow for more flexibility and leave a narrow window to establish selectivity [77]. As an add-on, LU-002i has been functionalized at the P2-site to create an activity-based probe (ABP) for the visualization of $\beta 2$ i-activity of human iCPs. Although LU-002i and its ABP derivative are functional in cell lysates, it is unknown whether they can penetrate cell membranes and are effective in vivo. To the best of our knowledge, LU-002i is the only $\beta 2 \mathrm{i}$-selective ligand known to date and it has not yet been tested for any biologically or therapeutically relevant in vivo effects.

\subsection{Inhibitors of Subunit $\beta 5 i$}

The ChT-L activities of $\beta 5$-subunits are by far the most important cleavage specificities of $\mathrm{CPs}$ and thus they are the target of most synthetic and natural proteasome inhibitors. As with $\beta 2$-subunits, the $\beta 5 c$ - and $\beta 5$ i-substrate binding channels only marginally differ in sequence and structure. The most pronounced distinction is the size of their S1-specificity pockets, originating from a conformational change of Met 45 . While in subunit $\beta 5$ c Met 45 flexibly arranges with various kinds of apolar amino acid side chains, preferentially leucine, the S1-pocket of $\beta 5 \mathrm{i}$ is enlarged and promotes cleavage after bulky hydrophobic residues such as Phe, Tyr or Trp [26]. Thus, by staffing inhibitors with large P1-residues, $\beta 5 i-$ selectivity can be gained.

Given the huge number and the structural heterogeneity of $\beta 5$ i-selective drugs published over the last years, their presentation and discussion is grouped according to mode of inhibition and structural features. 


\subsubsection{Non-Covalent Inhibitors}

In the hope for higher isoform selectivity compared to covalently acting compounds, several non-covalent and often non-peptidic iCP inhibitors with exquisite potency and $\beta 5 i$-selectivity have been identified over the last few years. While some already underwent several optimization steps, the smaller ones especially might serve as potent fragments for future extensions and modifications.

\section{Isolated Fragments}

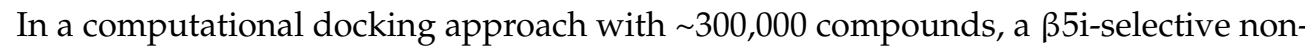
peptide fragment (compound 1; Figure 3) was discovered. Using purified human iCP, the $\mathrm{IC}_{50}$ value for $\beta 5 \mathrm{i}$ was determined as $1.7 \mu \mathrm{M}$. At $5 \mu \mathrm{M}$, $\beta 5 \mathrm{c}$ showed $80 \%$ residual activity, indicating that the compound preferentially targets $\beta 5$ i over $\beta 5$ c (Table 1) [78]. However, other proteasome activities have not been tested for co-inhibition, thus leaving questions about the selectivity. Further evaluation, e.g., by structural studies, is necessary to confirm the inhibition and to make use of the findings in rational drug design efforts.

\section{Psoralenes}

Another virtual screening identified psoralenes as potential iCP inhibitors. The nonpeptidic compound 3 (Figure 3 ) targets $\beta 5 i$ with 107 -fold selectivity over $\beta 5 c\left(K_{i}\right.$ values of $1.6 \mu \mathrm{M}$ for $\beta 5 \mathrm{i}$ and $172.2 \mu \mathrm{M}$ for $\beta 5 \mathrm{c}$; Table 1) [79]. It penetrates cell membranes and inhibits the iCP in cells with similar selectivity as ONX 0914 but 1000-fold lower potency. To enhance target affinity, compound 3 was functionalized with different electrophilic warheads [79] and further modifications were introduced to stimulate selectivity [102]. To make use of the psoralene scaffold in future fragment evolution or linking approaches, structural analysis of the binding mode of compound 3 or one of its derivatives to the $\mathrm{CP}$ might be useful.

\section{N,C-Capped Dipeptides}

In recent years, several non-covalently acting N,C-capped dipeptide and dipeptidomimetic inhibitors with $\beta 5$ i-selectivity have been reported $[100,103]$. Among them, the $\mathrm{N}, \mathrm{C}$-capped dipeptide DPLG3 (Figure 3). It targets subunit $\beta 5 \mathrm{i}$ with an $\mathrm{IC}_{50}$ value of 0.0045 $\mu \mathrm{M}$ and 7200 -fold selectivity over $\beta 5 c$, while other activities are inhibited $<50 \%$ at 33.3 $\mu \mathrm{M}$ (Table 1) [80]. DPLG3 suppresses cytokine release in vitro and shows efficacy in an animal heart transplantation model by significantly extending the graft survival time [80]. Although DPLG3 should not target subunits other than $\beta 5 i$ at the applied concentrations, in vivo inhibition values have not been reported and so it remains to be further investigated whether single-subunit inhibition is really sufficient for the observed therapeutic effects [47]. Due to its adverse physicochemical properties, i.e., high hydrophobicity and poor water solubility, as well as poor cell penetration ability, efforts to improve DPLG3 were undertaken and afforded several derivatives, among them PKS21272 with 500-fold $\beta 5 \mathrm{i}$-selectivity and $\mathrm{IC}_{50}$ values of $0.0012 \mu \mathrm{M}$ for $\beta 5 \mathrm{i}$ and $0.61 \mu \mathrm{M}$ for $\beta 5 \mathrm{c}$, as well as $<50 \%$ inhibition of other subunits at $33.3 \mu \mathrm{M}$ [104]. This compound is cell-penetrating and inhibits proteasomes in vivo but at lower selectivity (81-fold selectivity for iCP) and potency $(0.053 \mu \mathrm{M})$. In addition, PKS21272 can inhibit activation and proliferation of T cells [104]. Notably, derivatives of DPLG3 are claimed to be 'active site-directed non-competitive inhibitors' [64,104], meaning that their inhibition potency is not affected by accumulating substrate concentrations. Considering their peptidic or peptide-like structure and their binding to the natural $\beta 5$-substrate binding pockets [64], a non-competitive mode of action is questionable.

\section{Thiazole Compounds}

In 2014, Roche Diagnostics patented a set of non-peptidic compounds with pronounced $\beta 5$ i-selectivity and -potency [81]. This set of inhibitors is based on a thiazole core that features an aromatic bicyclic moiety at the C2-site linked to a carboxylic acid via a 
peptide bond. To resolve the binding mode of the ligands to the proteasomal active site and their basis for selectivity, the most potent ( $\mathrm{IC}_{50}$ value of $0.025 \mu \mathrm{M}$ for human $\beta 5 \mathrm{i}$ ) and selective (800-fold over $\beta 5 \mathrm{i}$ ) compound of this series [81], termed Ro19 (Figure 3), was studied by $X$-ray crystallography with a humanized yeast proteasome, featuring the human $\beta 5 \mathrm{i} / \beta 6$-substrate binding channel [105]. The X-ray data visualized that Ro19 occupies the S1-pocket and also S1/S3-sub-sites that are not accessible to natural peptide-based ligands but various synthetic compounds [106,107]. Ro19 and all other compounds of this class are $\beta 5 i$-selective, as their bulky quinolone moiety complies better with the spacious S1-pocket of $\beta 5 \mathrm{i}$ than with the smaller one of $\beta 5 \mathrm{c}$. In addition, binding to the active sites of $\beta 1 \mathrm{i}$ and $\beta 2 \mathrm{i}$ is precluded by steric hindrance of the thiazole ring with residues of their S3-pockets. Notably, Ro19 is a poor inhibitor of mouse $\beta 5 i$-probably because the mouse specific residue Met31 hinders its placing [105]. Proteasomal substrate binding channels are well conserved in sequence and structure among different species, but sub-pockets outside the natural ligand binding sites may not be. Thus, inhibitors with oversized P1-sites or non-standard binding modes like Ro19 may be associated with significant species-selectivity and demand for careful selection of animal models for preclinical studies. Similar observations were made with the covalent $\beta 5 i$-inhibitors PR-924 [106] and M3258 [66] (see Section 4.3.2.)

\subsubsection{Covalent Inhibitors}

The majority of $\beta 5$ i-inhibitors feature a reactive functional group that either reversibly or irreversibly links them to the nucleophilic Thr1 residue (see Section 2.2). However, this covalent mode of action usually gives rise to co-inhibition of unwanted activities and often dampens subunit selectivity, because all proteolytically active $\beta$-subunits of the $\mathrm{CP}$ share the same active site architecture and catalytic mechanism $[8,15,26]$. Alternative approaches therefore explore non-catalytic amino acids nearby the active site as nucleophiles.

\section{Inhibitors targeting Cys48 of $\beta 5 \mathrm{i}$}

The concept of targeting non-catalytic residues has been successfully applied to a wide range of enzymes, including the proteasome [108,109]. More recently, it has also been exploited for the development of $\beta 5$ i-selective inhibitors. Three independent studies selected Cys48 at the interface of the S2- and S4-specificity pockets as a nucleophilic target residue $[82,83,110]$. Because $\beta 5 c$ encodes a non-reactive Gly at this position [26], the strategies aimed for a strong covalent blockage of $\beta 5 \mathrm{i}$ and either no or a modest non-covalent inhibition of $\beta 5 c$. The concept of gaining subunit preferences by reactivity rather than noncovalent interactions is a smart approach pursued by several pharmaceutical companies.

Already, in 2015, Principia Biopharma Inc. filed a patent describing inhibitors that form a reversible covalent bond with the conserved non-catalytic Cys48 of $\beta 5 i$ [110]. The prototype compound PRN1126 (Figure 3) was shown to be $\sim 30$-fold selective for human $\beta 5 \mathrm{i}$ over human $\beta 5 \mathrm{c}\left(\mathrm{IC}_{50}\right.$ values determined for purified human $\mathrm{CCP}$ and $\mathrm{iCP}: 0.0072 \mu \mathrm{M}$ for $\beta 5 \mathrm{i}$ and $0.21 \mu \mathrm{M}$ for $\beta 5 \mathrm{c}$ ) without touching other proteasome activities (Table 1) [69]. Although being truly $\beta 5$ i-selective, PRN1126 dampened neither MHC-I surface expression nor interleukin (IL)-6 secretion, nor Th17 differentiation. In addition, no therapeutic benefit was noted in experimental models of autoimmune diseases [69], questioning the hitherto existing dogma that selective inhibition of $\beta 5 i$ translates into therapeutic potential. Notably, experimental proof for the proposed reaction mechanism of PRN1126 with Cys48 is still not available, but the nitrile functional group of PRN1126 (Figure 3) is supposed to approach Cys48 via the S2-pocket. Subsequent nucleophilic attack of the C-N triple bond by the thiol likely results in a reversible covalent thioimidate linkage [111].

Furthermore, a patent application of Merck KGaA from 2016 reports a group of $\beta 5 \mathrm{i}-$ selective compounds with $\mathrm{IC}_{50}$ values $<0.050 \mu \mathrm{M}$ and $\geq 150$-fold selectivity for $\beta 5 \mathrm{i}$ over $\beta 5$ c [82]. The compounds bear a boronic acid head group that targets Thr1, and a second electrophilefrequently an acrylamide moiety (such as in compound 16, Table 1, Figure 3) - that may function as a Michael acceptor in the reaction with Cys48 of subunit $\beta 5 \mathrm{i}$. Given their dipeptide structure, 
these boronic acid inhibitors are expected to target Cys48 like PRN1126 via the S2-pocket, but experimental proof for this reaction mechanism is not available.

In another study, Dubiella et al. designed a decarboxylated peptide that is derived from carfilzomib (Kyprolis ${ }^{\circledR}$ ) and directed to Cys48 via an electrophile at its P4-site [83]. Among the tested nucleophiles, the $\alpha$-chloroacetamide variant 1-CA was the most potent. Variant 1-CA showed nine-fold selectivity for $\beta 5 \mathrm{i}$ over $\beta 5 \mathrm{c}$, and did not target other subunits of human $\mathrm{CCP}$ or $\mathrm{iCP}$ [83]. Using a mutant yeast proteasome, the covalent reaction of the $\alpha$-chloroacetamide at P4 with Cys48 at the active site of $\beta 5$ was visualized and confirmed. Notably, yeast $\beta 1$ - and $\beta 2$-subunits also encode potential nucleophiles in their substrate binding channel, but in agreement with activity assays neither Ser48 of $\beta 1$ nor Thr $48 /$ Cys31 of $\beta 2$, nor Cys114 of $\beta 3$ reacted with 1-CA [83]. This notion is also in agreement with the subunit selectivity of PRN1126 [69]. Improvements of the peptide moiety of 1-CA finally led to 4-CA (Figure 3). Featuring a Asn residue at P3 that can hydrogen bond to Ser27 of $\beta 5 \mathrm{i}$ but not to Ala 27 of $\beta 5 c$, 4-CA showed improved $\beta 5$ i-potency $\left(\mathrm{IC}_{50} 0.64 \mu \mathrm{M}\right)$ and -selectivity (156-fold over $\beta 5 \mathrm{c}$; Table 1) [83].

Inhibitors Targeting Thr1

- Oxathiazolones

Oxathiazolones are assumed to irreversibly modify the proteasomal active site. Multiple compounds of this class have been investigated for their $\beta 5$ i-selectivity, with HT2004 performing the best with purified human CPs $\left(k_{i n a c t} / K_{i}\right.$ for $\beta 5 i$ : 1093; selectivity for $\beta 5 i$ over $\beta 5$ c: 4752; Table 1, Figure 3) [48]. Although oxathiazolones are able to penetrate cell membranes, their instability in water prevented further biological studies [48]. The oxathiazolone head group has also been installed on non-covalent psoralene fragments, ultimately resulting in a potent and selective inhibitor $\left(\mathrm{IC}_{50}\right.$ for purified human CPs: $0.106 \mu \mathrm{M}$ for $\beta 5 \mathrm{i}$; residual activity of other active sites is $\geq 67 \%$ at $10 \mu \mathrm{M})[79,102]$. Despite significant improvements, poor cell penetration prevented further investigations [102].

- Piperlongumine

Piperlongumine is a pepper alkaloid that features a vinylamide group similar to CP inhibitors of the syrbactin class (Figure 3). By structural analogy, piperlongumine was proposed to irreversibly modify the active site Thr1 of proteasome subunits in a Michaeltype 1,4-addition [84,112]. In enzyme assays with human $\mathrm{CCP}$ and $\mathrm{iCP}$, piperlongumine was found to block $\beta 5 \mathrm{i}$ with an $\mathrm{IC}_{50}$ value of $15 \mu \mathrm{M}$, while $\beta 5 \mathrm{c}$ and $\beta 1 \mathrm{c}$ were inhibited $<30 \%$ at $50 \mu \mathrm{M}$ (Table 1). However, other catalytic sites of the proteasome were not tested for potential co-inhibition. The cytotoxic effects of piperlongumine have been linked to various molecular mechanisms, including oxidative stress, DNA damage and apoptosis [113], suggesting that $\mathrm{iCP}$ inhibition might only in part contribute to this biological activity [84].

- Boronates

In the search for boronic acids that are not bioactivated by oxidative deboronation [58] and carry a non-peptidic scaffold, a virtual compound library was screened by molecular docking. Hits that were predicted to adopt a Ro19-like binding mode [105] were prioritized. Among the identified compounds, 1a (Figure 3; originally published as 1) is ranked the highest, as it shows modest affinity for $\beta 5 \mathrm{i}$ ( $\mathrm{IC}_{50}$ value for purified human iCP: $34 \mu \mathrm{M}$ ) and moderate selectivity over $\beta 5$ c (three-fold; Table 1) [85]. However, a complete $\mathrm{cCP}$ and iCP subunit selectivity profile has not been determined. Considering the high reactivity of boronic acid compounds in general and the low potency of $1 \mathrm{a}$, the potential of this agent as a CP ligand is considered rather low, but the scaffold might inspire future fragment-based inhibitor design strategies.

In a joint venture, Genentech Inc. and Proteros Biostructures $\mathrm{GmbH}$ determined the $\mathrm{X}$-ray structure of the human $\mathrm{iCP}$ in complex with a $\beta 1 \mathrm{i}$ - and $\beta 5 \mathrm{i}$-selective boronic acid [65] (see also Section 5.3), patented by Roche [90]. Based on these structural data, the highly $\beta 5$ i-selective compound 22 (IC 50 value for purified iCP: $0.0041 \mu \mathrm{M}$ for $\beta 5 \mathrm{i} ; 2219$-fold selective over $\beta 5 c$; Table 1, Figure 3) was designed. Yet, $\beta 2$-inhibition values have not been 
reported. The inhibitor did not induce cell death in immune cells, but was not tested for its potential to lower proinflammatory cytokines [65].

Besides, peptidic boronates with $\beta 5$ i-selectivity have been reported by Merck KGaA. In addition to the bifunctional ones discussed above [82], the company developed M3258 (Figure 3), an orally-available $\beta 5$ i-selective inhibitor with 614 -fold selectivity over $\beta 5 \mathrm{c}$ and all other catalytic sites of $\mathrm{CCP}$ and $\mathrm{iCP}\left(\mathrm{IC}_{50}\right.$ value for purified iCP: $\left.0.0041 \mu \mathrm{M}\right)$ and favorable pharmacokinetic properties [66,114]. M3258 carries a bulky 3-benzofuranyl moiety that, together with the single amide group, dictates $\beta 5$ i-selectivity [115]. M3258 has strong anti-tumor activity in several multiple myeloma models, including those refractory to bortezomib, and reduces various cytokines, including IL-6 and TNF $\alpha$ levels [66]. Remarkably, the agent has fewer side effects compared with its structural analogues bortezomib (Velcade ${ }^{\circledR}$ ) and ixazomib (Ninlaro ${ }^{\circledR}$ ) that target both $\beta 5 c$ - and $\beta 5$ i-subunits $[66,116]$. It is currently under evaluation in a phase I study as a single agent or combination therapy with dexamethasone for the treatment of patients with relapsed refractory multiple myeloma (NCT04075721) [66].

\section{- $\quad$ Peptide epoxyketone inhibitors}

In 2009, scientists of Proteolix Inc. published the $\beta 5$ i-selective compound PR-924 [86]. PR-924, a tripeptide epoxyketone inhibitor carrying a non-natural D-Ala residue at P3 (Figure 3), has high potency and selectivity for $\beta 5 \mathrm{i}\left(\mathrm{IC}_{50}\right.$ values: $0.022 \mu \mathrm{M}$ for $\beta 5 \mathrm{i}, 2.9$ $\mu \mathrm{M}$ for $\beta 5 \mathrm{c}, 8.2 \mu \mathrm{M}$ for $\beta 1 \mathrm{i}$ and $>30 \mu \mathrm{M}$ for $\beta 1 \mathrm{c}, \beta 2 \mathrm{c}$ and $\beta 2 \mathrm{i} ; \beta 5 \mathrm{c} / \beta 5 \mathrm{i}$ ratio: 131) [86], though it was not tested for effectiveness in autoimmune diseases. Instead, it was reported that PR-924 selectively induces cell death of human multiple myeloma cell lines and suppresses grafted multiple myeloma in mice [117]. However, these anti-proliferative effects required high drug concentrations that were likely not compatible with isoformselective CP inhibition [118].

Despite these unsatisfactory results, the unusual stereochemistry of PR-924 and its exceptional $\beta 5 i$-selectivity were further investigated by academic groups. Derivatives of PR-924, combining various P1- and P2-residues as well as N-cap structures with a D-Ala residue at $\mathrm{P} 3$, were designed and evaluated for their subunit selectivity. Among them, LU-035i emerged as the most potent and selective compound $\left(\mathrm{IC}_{50}\right.$ values in Raji cell lysates: $0.011 \mu \mathrm{M}$ for $\beta 5 \mathrm{i} ; \beta 5 i-s e l e c t i v i t y: 500$ over $\beta 5 \mathrm{c}$; Table 1 ) [73]. In the course of this study it was noted that inhibitors with a P3-D-Ala residue and a 3-methyl-1Hindene N-cap, like PR-924 and LU-035i, display high $\beta 5$ i-selectivity (Table 1). Notably, this effect was not based on enhanced $\beta 5$ i-potency, but rather due to poor inhibition of $\beta 5 \mathrm{c}$. As initial structural data could not explain this difference in performance [73], X-ray crystallographic data with humanized yeast proteasomes were collected. The structures visualized distinct binding modes for PR-924 in $\beta 5 c / \beta 6$ - and $\beta 5 \mathrm{i} / \beta 6$-substrate binding channels, respectively [106]. Consistent with the non-natural stereochemistry at P3, PR924 adopts a kinked conformation in humanized $\beta 5 i$-proteasome structures, with the $\mathrm{N}$-cap occupying a $3^{*}$-sub-pocket that cannot be approached by natural ligands. By contrast, at the $\beta 5 \mathrm{c} / \beta 6$-active site and in yeast $\mathrm{CP}$ crystal structures, PR-924 adopts a linear conformation that is assumed to be energetically disfavored and associated with poor affinity, thereby causing enhanced $\beta 5$ i-selectivity [106]. This effect applies to all derivatives of PR-924 with a P3-D-Ala residue and a 3-methyl-1H-indene cap, and was also found by two independent modelling studies [87,119]. Inhibitors with smaller $\mathrm{N}$-caps bind to $\beta 5 \mathrm{c}$ and $\beta 5 \mathrm{i}$ in their kinked mode and thus lose $\beta 5 \mathrm{i}$-selectivity. This result also indicates that the $\mathrm{S}^{*}$-sub-pocket is larger in $\beta 5 \mathrm{i}$ than in $\beta 5 \mathrm{c}$, although no pronounced structural differences could be spotted so far to explain the distinct binding modes. Furthermore, PR-924 and its derivatives show high selectivity for human $\beta 5 i$ ( $>130$-fold over $\beta 5 c)$ but significantly lower preference for mouse $\beta 5 \mathrm{i}$ (16-fold over mouse $\beta 5 \mathrm{c}$ ). While Val31 of human $\beta 5 \mathrm{i}$ is compatible with PR-924 binding, Met31 of mouse $\beta 5 \mathrm{i}$ sterically interferes with the kinked binding mode of PR-924, as well as its derivatives [106]. Usually, most inhibitors target proteasomes from distinct species with comparable potency, as the substrate binding channels are similar in primary, secondary and tertiary structure. However, when targeting 
non-canonical sites aside from the natural substrate binding pockets, the amino acids are not that well conserved. This fact complicates drug development and evaluation in preclinical studies, as different species can produce different outcomes. Therefore, animals for preclinical trials have to be carefully chosen and any disagreement in the amino acid lining of inhibitor target sites needs to be evaluated beforehand. In this regard, the ligand binding site of the target protein should be studied by structural means in early drug development stages.

Only recently, Kezar Life Sciences Inc. reported another $\beta 5$ i-selective inhibitor (compound 8 (Figure 3, Table 1); $\mathrm{IC}_{50}$ values determined in MOLT-4 cell lysates: $0.034 \mu \mathrm{M}$ for $\beta 5 \mathrm{i}$; 78-fold selectivity for $\beta 5 \mathrm{i}$ over $\beta 5 \mathrm{c}$ ) [87]. Notably, compound 8 failed to control cytokine release in in vitro studies and disease progression in mice suffering from active collagen antibody-induced arthritis [87]. This report further substantiates the suspicion that single-subunit-selective inhibitors are poorly active as therapeutic agents (see also Section 5).

\subsection{Therapeutic Potential of Subunit-Selective iCP Inhibitors}

The identification of numerous highly subunit-selective inhibitors and more sophisticated methods to assay proteasome activities in vitro and in vivo allowed for a more thorough analysis of the biological effects and medicinal potential of iCP inhibition. These studies questioned the initial assumption that blockage of a single $\mathrm{iCP}$ subunit like $\beta 5 \mathrm{i}$ is sufficient to cause therapeutic benefits in autoimmune diseases.

Among the $\beta 1$ i-inhibitors, ML604440, KZR-504 and LU-001i failed to generate therapeutically relevant responses $[76,87,91,93]$, and the anti-cancer activity reported for UK101 [97] likely arises from co-inhibition of other CP activities [98]. Whether the beneficial effects of DB-310 in Alzheimer's disease result from co-inhibition of other proteasome subunits as well, or from disease-specific circumstances, needs to be further explored [75]. In this regard, it is worth mentioning that most compounds are evaluated for their efficacy in different disease models and distinct settings, precluding any systematic comparison and reliable judgement of their bioactivity. For example, in the central nervous system, iCP inhibition has recently been correlated with disease worsening instead of improvement, thus demanding for careful selection of preclinical models [120].

Regarding $\beta 5$ i-selective inhibitors, PRN1126, compound 8 (Kezar Life Sciences Inc.) and compound 22 (Genentech Inc.) were found to be therapeutically inactive $[65,69,87]$. Whereas the reason for failure of PRN1126 and compound 8 was attributed to their singlesubunit inhibition profile $[69,87]$, Genentech Inc. argued that immune cells undermine iCP inhibition by inducing cCP expression, and thus escape apoptosis [65]. Notably, the study of Genentech Inc. aimed at inducing cell death in immune cells, while others including Kezar Life Sciences Inc. looked for a reduction in cytokine production without compromising cell viability. Although the outlined discrepancies may result from differences in read-out, target applications, applied concentrations etc., further evaluations are certainly required. For PR-924 [117] and M3258 [66], pronounced anti-cancer activity has been described in multiple myeloma tumor models. However, the effects observed for PR-924 are suspected to originate from co-inhibition of other CP activities [118]. It thus remains to be evaluated whether the activity of M3258 indeed results from single-subunit inhibition or from a high $\beta 5 i$-dependence of multiple myeloma cells as proposed by the authors [66]. In summary, with few exceptions, iCP inhibitors with high single-subunit selectivity appear to not have the expected therapeutic effects in vitro and in preclinical animal models of autoimmune diseases [47].

\section{Pan-Immunoproteasome Reactive Inhibitors}

Increasing evidence for the therapeutic failure of single-subunit-selective iCP inhibitors in inflammatory diseases promoted the search for compounds that target at least two iCP subunits. Specifically, co-inhibition of $\beta 1 i$ and $\beta 5 i$, or $\beta 2 i$ and $\beta 5 i$, appears to drive anti-inflammatory activity [87]. Based on these findings, the collection of known pan- 
reactive $\mathrm{iCP}$ inhibitors was recently supplemented by new compounds and will certainly grow further in the future.

\subsection{Non-Covalent Amides}

Ettari et al. recently published the non-covalent amide 6 (Figure 3 ) that targets $\beta 1 \mathrm{i}$ and $\beta 5 \mathrm{i}$-subunits of the iCP $\left(\mathrm{K}_{i}\right.$ values for purified human CPs: $4.9 \mu \mathrm{M}$ for $\beta 1 \mathrm{i}$ and $4.4 \mu \mathrm{M}$ for $\beta 5 \mathrm{i}$; Table 1) and inhibits proliferation of a dexamethasone-resistant human multiple myeloma cell line $\left(\mathrm{EC}_{50}: 17.8 \mu \mathrm{M}\right)$ [88]. As inhibition values for the corresponding $\mathrm{CCP}$ subunits have not been determined, the iCP selectivity of amide 6 is elusive and remains to be proven.

\subsection{IPSI-001}

Initially declared as a $\beta 1$ i-specific inhibitor, IPSI-001 was one of the first iCP-selective compounds. This peptide aldehyde, also known as calpeptin (Figure 3), was shown to target subunit $\beta 1 \mathrm{i}$ of the iCP and induce apoptosis in multiple myeloma cells [89], but later this bioactivity was claimed to result from co-inhibition of $\beta 5 c-$ and $\beta 5 i$-subunits [86]. Detailed and accurate evaluation of the subunit selectivity profile of IPSI-001 is essential to assess its potential as pan-reactive iCP inhibitor. To this end, further optimizations with respect to potency, stability and cross-reactivity might be required. So far, the low potency of IPSI-001 precluded in vivo studies [89]. Moreover, its aldehyde head group is prone to oxidative inactivation and well known to co-inhibit serine and cysteine proteases [121]. The latter feature can be beneficial to potential applications due to synergistic effects, or detrimental because of unwanted side effects.

\subsection{Boronates}

A patent filed by Roche reports about substituted triazole boronic acid compounds, among which ligand $1 \mathrm{~b}$ (Figure 3 ; originally published as 1 ) has pronounced $\beta 1 \mathrm{i}$ - and $\beta 5 \mathrm{i}$ selectivity ( $\mathrm{IC}_{50}$ values of $0.002 \mu \mathrm{M}$ for $\beta 5 \mathrm{i}$ and $0.039 \mu \mathrm{M}$ for $\beta 5 \mathrm{c}$, as well as $0.004 \mu \mathrm{M}$ for $\beta 1 \mathrm{i}$ and $0.32 \mu \mathrm{M}$ for $\beta 1 \mathrm{c}$ ) [90]. Based on this report, Genentech Inc. and Proteros Biostructures $\mathrm{GmbH}$ created derivatives of $1 \mathrm{~b}$ that are even more selective $\beta 5 \mathrm{i}-/ \beta 1 \mathrm{i}$-inhibitors [65]. The compounds were not cytotoxic to immune cells, but anti-inflammatory activity was not examined.

\section{4. $L U-005 i$}

A screen of ONX 0914 derivatives for improved $\beta 5$ i-selectivity led to the identification of LU-005i. Instead of a Phe residue, LU-005i features a cyclohexyl moiety at P1 (Figure 3) [73]. It shows activity towards subunits $\beta 1 \mathrm{i}, \beta 2 \mathrm{i}$ and $\beta 5 \mathrm{i}$ with decent selectivity over the respective constitutive subunits ( $\mathrm{IC}_{50}$ values for purified CPs: $0.052 \mu \mathrm{M}$ for $\beta 1 \mathrm{i}$, $0.47 \mu \mathrm{M}$ for $\beta 2 \mathrm{i}$ and $0.16 \mu \mathrm{M}$ for $\beta 5 \mathrm{i} ; \beta 1 \mathrm{c} / \beta 1 \mathrm{i}$ ratio: $>19 ; \beta 2 \mathrm{c} / \beta 2 \mathrm{i}$ ratio: $6 ; \beta 5 \mathrm{c} / \beta 5 \mathrm{i}$ ratio: 18 ; Table 1 ) and thus is considered a pan-immunoproteasome-selective inhibitor [91]. As the first reported compound that targets all three iCP subunits over the respective constitutive subunits, LU-005i was probed for its biological activity and therapeutic potential. These studies revealed that LU-005i is able to lower MHC-I surface expression and cytokine production. Moreover, LU-005i blocks differentiation of Th17 helper cells and alleviates symptoms of dextran sulfate sodium-induced colitis in mice [91].

\subsection{ONX 0914}

Reported in 2009, ONX 0914 (formerly PR-957) was the first CP inhibitor with moderate $\beta 5$ i-selectivity (nine-fold over $\beta 5 \mathrm{c}$ ) and emerged as the lead compound for iCP inhibitor development in general (Table 1, Figure 3) [63]. In vitro, it reduces MHC-I expression, presentation of $\beta 5 \mathrm{i}$-dependent antigens, as well as cytokine production and blocks Th17 differentiation [63]. ONX 0914 selectively induces apoptosis of CD14 ${ }^{+}$monocytes, thereby reducing IL-23 production and suppressing Th17 differentiation [122]. The potential of ONX 0914 to serve as a new treatment of chronic inflammations and autoimmune diseases 
was initially shown in mouse models of rheumatoid arthritis and diabetes mellitus type I [63], and later confirmed in a plethora of other preclinical studies, including experimental colitis [123], myasthenia gravis [124], Hashimoto's thyroiditis [125], systemic lupus erythematosus [126], immune thrombocytopenia [93], experimental neuritis [127], autoimmune myocarditis [128] and multiple sclerosis [120,129] (for a complete list see [47]). In addition, as exemplified with ONX 0914, the iCP might qualify as a target to prevent transplant rejection [130], graft-versus-host disease [131] and pathogen-induced immunopathology [132]. Despite this excellent performance without cytotoxic side effects [133], unfavorable solubility properties of ONX 0914 prevented its evaluation in clinical trials [87].

The beneficial effects found with ONX 0914 were initially attributed to its $\beta 5 i$-selectivity. The development of inhibitors with improved subunit selectivity profiles, however, revealed that $\beta 5 \mathrm{i}$-selective compounds are inferior to ONX 0914 with respect to biological activity in autoimmune diseases. Reassessment of ONX 0914 finally uncovered a substantial co-inhibition of $\sim 60 \%$ of subunit $\beta 1 \mathrm{i}$ and marginal $\beta 2 \mathrm{i}$-blockage at efficacious doses [87]. Most likely, this combined iCP subunit inhibition, or at least partial blockage of a second site, is required for the anti-inflammatory features of ONX 0914 [87]. Experimental proof for this theory was provided by assays with combinations of subunit-selective inhibitors.

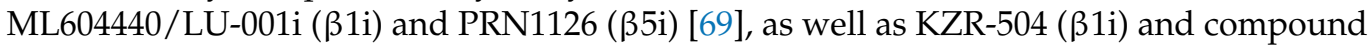
8 ( $\beta 5 \mathrm{i}$ ) [87], efficiently suppressed cytokine expression, while the single agents or combinations of $\beta 1 \mathrm{i}$ - and dual $\beta 2 \mathrm{c} / \beta 2 \mathrm{i}$-inhibitors failed. In fact, a combination of compound 8, KZR-504 and a $\beta 2$-inhibitor, mimicking pan-iCP reactivity, was most effective but also killed $30 \%$ of stimulated immune cells [87]. While in the beginning ONX 0914 was the only available compound to study physiological effects of iCP inhibition, a plenitude of compounds is now available to assess all kinds of subunit combinations in detail for their bioactivity and to balance the right inhibition strength for the desired application. This is particularly important, as ONX 0914 was found to have adverse effects on disease progression when applied in the chronic phase of a mouse model of multiple sclerosis [120].

\subsection{KZR-616}

In an effort to find a compound with a similar subunit selectivity profile as ONX 0914 but improved physico-chemical properties for clinical applications, Kezar Life Sciences Inc. (formerly Onyx Pharmaceuticals Inc.) developed KZR-616 [87]. KZR-616 potently co-inhibits subunits $\beta 1 \mathrm{i}$ and $\beta 5 \mathrm{i}$ of $\mathrm{iCPs}\left(\mathrm{IC}_{50}\right.$ values for human cell lysates: $0.039 \mu \mathrm{M}$ for $\beta 5 \mathrm{i}$ and 0.131 $\mu \mathrm{M}$ for $\beta 1 \mathrm{i} ; \beta 1 \mathrm{c} / \beta 1 \mathrm{i}$ ratio: $>80 ; \beta 5 \mathrm{c} / \beta 5 \mathrm{i}$ ratio: 17 ; Table 1 , Figure 3 ) and displays broad antiinflammatory activity [134]. Due to its superior activity in rheumatic diseases and its favorable physicochemical properties compared with ONX $0914[135,136]$, it rapidly entered phase I trials for safety evaluation. Although the compound was found to be well tolerated, prednisone and antihistamines were required to prevent systemic drug reactions upon first administration of KZR-616 [137]. In agreement with preclinical investigations that ruled out inhibition of intracellular proteases other than the CP [87], no cytotoxic effects were observed [137]. Furthermore, the immune system was not generally compromised. At an applied dose of $45 \mathrm{mg}$, KZR-616 blocks $\sim 95 \%$ of $\beta 5 \mathrm{i}$ and $\sim 70 \%$ of $\beta 2 \mathrm{i}$ [137]. This positive rating allowed KZR-616 to enter a phase $\mathrm{Ib} / \mathrm{II}$ trial in patients suffering from systemic lupus erythematosus with and without lupus nephritis (NCT03393013), and in two phase II studies for active polymyositis or dermatomyositis (NCT04033926), as well as active autoimmune hemolytic anemia or immune thrombocytopenia (NCT04039477). Due to the COVID-19 pandemic, the latter trial was recently withdrawn before first patients were enrolled. Combined, KZR-616 has the potential to advance to a novel and effective therapy for chronic inflammatory diseases in the future and to bring selective iCP inhibition to clinical application. This encouraging development will certainly promote other pharmaceutical companies to raise their budget for proteasome inhibitor research. 


\section{Conclusions}

During the last decade, the iCP emerged as a drug target for various diseases. While chronic inflammations and hematological cancers range at the forefront of this development, other potential applications such as treatment of solid tumors, neurodegenerative disorders and infectious diseases either need further exploration or are just entering the stage. Only time can tell us whether the iCP will be approved as a druggable target and whether another chapter can be added to the success story of CP inhibition.

Either way, it is almost certain that the clinical utility of $\mathrm{CP}$ inhibitors in general will be expanded in the future, at least in the form of combination therapies to overcome resistances or for the treatment of non-responders. Aside from CP inhibitors, numerous compounds targeting CP-associated proteins, such as the 19S-cap, are in development [138] and may find their application as well, thus guaranteeing the proteasome, in any case, a prospering future.

Author Contributions: Writing—original draft preparation, E.M.H.; writing—review and editing, M.G. All authors have read and agreed to the published version of the manuscript.

Funding: This research was supported by the German Research Foundation (DFG, Grant No. 1861/10-3 to M.G.) and the Young Scholars' Program of the Bavarian Academy of Sciences and Humanities (E.M.H.).

Institutional Review Board Statement: Not applicable.

Informed Consent Statement: Not applicable.

Data Availability Statement: Not applicable.

Acknowledgments: This work is dedicated to Robert Huber on the occasion of his 85th birthday.

Conflicts of Interest: The authors declare no conflict of interest.

\section{References}

1. Clarke, D.J. Proteolysis and the cell cycle. Cell Cycle 2002, 1, 233-234. [CrossRef]

2. Liu, H.; Urbe, S.; Clague, M.J. Selective protein degradation in cell signalling. Semin. Cell Dev. Biol. 2012, 23, 509-514. [CrossRef]

3. Ciechanover, A. The ubiquitin-proteasome proteolytic pathway. Cell 1994, 79, 13-21. [CrossRef]

4. Voges, D.; Zwickl, P.; Baumeister, W. The 26S proteasome: A molecular machine designed for controlled proteolysis. Annu. Rev. Biochem. 1999, 68, 1015-1068. [CrossRef]

5. Grawert, M.A.; Groll, M. Exploiting nature's rich source of proteasome inhibitors as starting points in drug development. Chem. Commun. 2012, 48, 1364-1378. [CrossRef]

6. Fricker, L.D. Proteasome Inhibitor Drugs. Annu. Rev. Pharmacol. Toxicol. 2020, 60, 457-476. [CrossRef] [PubMed]

7. Lowe, J.; Stock, D.; Jap, B.; Zwickl, P.; Baumeister, W.; Huber, R. Crystal structure of the 20 S proteasome from the archaeon T. acidophilum at 3.4 A resolution. Science 1995, 268, 533-539. [CrossRef] [PubMed]

8. Groll, M.; Ditzel, L.; Löwe, J.; Stock, D.; Bochtler, M.; Bartunik, H.D.; Huber, R. Structure of $20 \mathrm{~S}$ proteasome from yeast at $2.4 \AA$ resolution. Nature 1997, 386, 463-471. [CrossRef]

9. Groll, M.; Bajorek, M.; Kohler, A.; Moroder, L.; Rubin, D.M.; Huber, R.; Glickman, M.H.; Finley, D. A gated channel into the proteasome core particle. Nat. Struct. Biol. 2000, 7, 1062-1067. [CrossRef]

10. Kohler, A.; Cascio, P.; Leggett, D.S.; Woo, K.M.; Goldberg, A.L.; Finley, D. The axial channel of the proteasome core particle is gated by the Rpt2 ATPase and controls both substrate entry and product release. Mol. Cell. 2001, 7, 1143-1152. [CrossRef]

11. Kunjappu, M.J.; Hochstrasser, M. Assembly of the 20S proteasome. Biochim. Biophys. Acta 2014, 1843, 2-12. [CrossRef] [PubMed]

12. Stadtmueller, B.M.; Hill, C.P. Proteasome activators. Mol. Cell 2011, 41, 8-19. [CrossRef] [PubMed]

13. Coux, O.; Tanaka, K.; Goldberg, A.L. Structure and functions of the $20 \mathrm{~S}$ and $26 \mathrm{~S}$ proteasomes. Annu. Rev. Biochem. 1996, 65, 801-847. [CrossRef]

14. Heinemeyer, W.; Fischer, M.; Krimmer, T.; Stachon, U.; Wolf, D.H. The active sites of the eukaryotic $20 \mathrm{~S}$ proteasome and their involvement in subunit precursor processing. J. Biol. Chem. 1997, 272, 25200-25209. [CrossRef]

15. Huber, E.M.; Heinemeyer, W.; Li, X.; Arendt, C.S.; Hochstrasser, M.; Groll, M. A unified mechanism for proteolysis and autocatalytic activation in the $20 \mathrm{~S}$ proteasome. Nat. Commun. 2016, 7, 10900. [CrossRef] [PubMed]

16. Rock, K.L.; Goldberg, A.L. Degradation of cell proteins and the generation of MHC class I-presented peptides. Annu. Rev. Immunol. 1999, 17, 739-779. [CrossRef]

17. Michalek, M.T.; Grant, E.P.; Gramm, C.; Goldberg, A.L.; Rock, K.L. A role for the ubiquitin-dependent proteolytic pathway in MHC class I-restricted antigen presentation. Nature 1993, 363, 552-554. [CrossRef] 
18. Monaco, J.J. A molecular model of MHC class-I-restricted antigen processing. Immunol. Today 1992, 13, 173-179. [CrossRef]

19. Neefjes, J.; Jongsma, M.L.; Paul, P.; Bakke, O. Towards a systems understanding of MHC class I and MHC class II antigen presentation. Nat. Rev. Immunol. 2011, 11, 823-836. [CrossRef]

20. Groettrup, M.; Kirk, C.J.; Basler, M. Proteasomes in immune cells: More than peptide producers? Nat. Rev. Immunol. 2010, 10, 73-78. [CrossRef]

21. Volker, C.; Lupas, A.N. Molecular evolution of proteasomes. Curr. Top. Microbiol. Immunol. 2002, 268, 1-22. [CrossRef]

22. Kniepert, A.; Groettrup, M. The unique functions of tissue-specific proteasomes. Trends Biochem. Sci. 2014, 39, 17-24. [CrossRef] [PubMed]

23. Harshbarger, W.; Miller, C.; Diedrich, C.; Sacchettini, J. Crystal structure of the human 20S proteasome in complex with carfilzomib. Structure 2015, 23, 418-424. [CrossRef] [PubMed]

24. Unno, M.; Mizushima, T.; Morimoto, Y.; Tomisugi, Y.; Tanaka, K.; Yasuoka, N.; Tsukihara, T. The structure of the mammalian 20S proteasome at 2.75 A resolution. Structure 2002, 10, 609-618. [CrossRef]

25. Schrader, J.; Henneberg, F.; Mata, R.A.; Tittmann, K.; Schneider, T.R.; Stark, H.; Bourenkov, G.; Chari, A. The inhibition mechanism of human $20 S$ proteasomes enables next-generation inhibitor design. Science 2016, 353, 594-598. [CrossRef]

26. Huber, E.M.; Basler, M.; Schwab, R.; Heinemeyer, W.; Kirk, C.J.; Groettrup, M.; Groll, M. Immuno- and constitutive proteasome crystal structures reveal differences in substrate and inhibitor specificity. Cell 2012, 148, 727-738. [CrossRef]

27. Falk, K.; Rotzschke, O.; Stevanovic, S.; Jung, G.; Rammensee, H.G. Allele-specific motifs revealed by sequencing of self-peptides eluted from MHC molecules. Nature 1991, 351, 290-296. [CrossRef]

28. Engelhard, V.H. Structure of peptides associated with MHC class I molecules. Curr. Opin. Immunol. 1994, 6, 13-23. [CrossRef]

29. Driscoll, J.; Brown, M.G.; Finley, D.; Monaco, J.J. MHC-linked LMP gene products specifically alter peptidase activities of the proteasome. Nature 1993, 365, 262-264. [CrossRef]

30. Aki, M.; Shimbara, N.; Takashina, M.; Akiyama, K.; Kagawa, S.; Tamura, T.; Tanahashi, N.; Yoshimura, T.; Tanaka, K.; Ichihara, A. Interferon-gamma induces different subunit organizations and functional diversity of proteasomes. J. Biochem. 1994, 115, 257-269. [CrossRef]

31. Groettrup, M.; Kraft, R.; Kostka, S.; Standera, S.; Stohwasser, R.; Kloetzel, P.M. A third interferon-gamma-induced subunit exchange in the $20 \mathrm{~S}$ proteasome. Eur. J. Immunol. 1996, 26, 863-869. [CrossRef] [PubMed]

32. Murata, S.; Sasaki, K.; Kishimoto, T.; Niwa, S.; Hayashi, H.; Takahama, Y.; Tanaka, K. Regulation of CD8+ T cell development by thymus-specific proteasomes. Science 2007, 316, 1349-1353. [CrossRef] [PubMed]

33. Xing, Y.; Jameson, S.C.; Hogquist, K.A. Thymoproteasome subunit-beta5T generates peptide-MHC complexes specialized for positive selection. Proc. Natl. Acad. Sci. USA 2013, 110, 6979-6984. [CrossRef]

34. Tomaru, U.; Konno, S.; Miyajima, S.; Kimoto, R.; Onodera, M.; Kiuchi, S.; Murata, S.; Ishizu, A.; Kasahara, M. Restricted Expression of the Thymoproteasome Is Required for Thymic Selection and Peripheral Homeostasis of CD8(+) T Cells. Cell Rep. 2019, 26, 639-651.e2. [CrossRef] [PubMed]

35. Gomez, H.L.; Felipe-Medina, N.; Condezo, Y.B.; Garcia-Valiente, R.; Ramos, I.; Suja, J.A.; Barbero, J.L.; Roig, I.; Sanchez-Martin, M.; de Rooij, D.G.; et al. The PSMA8 subunit of the spermatoproteasome is essential for proper meiotic exit and mouse fertility. PLoS Genet. 2019, 15, e1008316. [CrossRef]

36. Qian, M.X.; Pang, Y.; Liu, C.H.; Haratake, K.; Du, B.Y.; Ji, D.Y.; Wang, G.F.; Zhu, Q.Q.; Song, W.; Yu, Y.; et al. Acetylation-mediated proteasomal degradation of core histones during DNA repair and spermatogenesis. Cell 2013, 153, 1012-1024. [CrossRef]

37. Uechi, H.; Hamazaki, J.; Murata, S. Characterization of the testis-specific proteasome subunit alpha4s in mammals. J. Biol. Chem. 2014, 289, 12365-12374. [CrossRef]

38. Guillaume, B.; Chapiro, J.; Stroobant, V.; Colau, D.; Van Holle, B.; Parvizi, G.; Bousquet-Dubouch, M.P.; Theate, I.; Parmentier, N.; Van den Eynde, B.J. Two abundant proteasome subtypes that uniquely process some antigens presented by HLA class I molecules. Proc. Natl. Acad. Sci. USA 2010, 107, 18599-18604. [CrossRef]

39. Klare, N.; Seeger, M.; Janek, K.; Jungblut, P.R.; Dahlmann, B. Intermediate-type 20 S proteasomes in HeLa cells: “Asymmetric" subunit composition, diversity and adaptation. J. Mol. Biol. 2007, 373, 1-10. [CrossRef]

40. De Bruin, G.; Xin, B.T.; Florea, B.I.; Overkleeft, H.S. Proteasome Subunit Selective Activity-Based Probes Report on Proteasome Core Particle Composition in a Native Polyacrylamide Gel Electrophoresis Fluorescence-Resonance Energy Transfer Assay. J. Am. Chem. Soc. 2016, 138, 9874-9880. [CrossRef]

41. Rock, K.L.; Gramm, C.; Rothstein, L.; Clark, K.; Stein, R.; Dick, L.; Hwang, D.; Goldberg, A.L. Inhibitors of the proteasome block the degradation of most cell proteins and the generation of peptides presented on MHC class I molecules. Cell 1994, 78, 761-771. [CrossRef]

42. Thibaudeau, T.A.; Smith, D.M. A Practical Review of Proteasome Pharmacology. Pharmacol. Rev. 2019, 71, 170-197. [CrossRef] [PubMed]

43. Cromm, P.M.; Crews, C.M. The Proteasome in Modern Drug Discovery: Second Life of a Highly Valuable Drug Target. ACS Cent. Sci. 2017, 3, 830-838. [CrossRef]

44. Ito, S. Proteasome Inhibitors for the Treatment of Multiple Myeloma. Cancers 2020, 12, 265. [CrossRef]

45. Park, J.E.; Miller, Z.; Jun, Y.; Lee, W.; Kim, K.B. Next-generation proteasome inhibitors for cancer therapy. Transl. Res. 2018, 198, 1-16. [CrossRef] 
46. Cenci, S.; Oliva, L.; Cerruti, F.; Milan, E.; Bianchi, G.; Raule, M.; Mezghrani, A.; Pasqualetto, E.; Sitia, R.; Cascio, P. Pivotal Advance: Protein synthesis modulates responsiveness of differentiating and malignant plasma cells to proteasome inhibitors. $J$. Leukoc. Biol. 2012, 92, 921-931. [CrossRef] [PubMed]

47. Basler, M.; Groettrup, M. Recent insights how combined inhibition of immuno/proteasome subunits enables therapeutic efficacy. Genes Immun. 2020, 21, 273-287. [CrossRef]

48. Fan, H.; Angelo, N.G.; Warren, J.D.; Nathan, C.F.; Lin, G. Oxathiazolones Selectively Inhibit the Human Immunoproteasome over the Constitutive Proteasome. ACS Med. Chem. Lett. 2014, 5, 405-410. [CrossRef]

49. Beck, P.; Dubiella, C.; Groll, M. Covalent and non-covalent reversible proteasome inhibition. Biol. Chem. 2012, 393, 1101-1120. [CrossRef]

50. Kaffy, J.; Bernadat, G.; Ongeri, S. Non-covalent proteasome inhibitors. Curr. Pharm. Des. 2013, 19, 4115-4130. [CrossRef] [PubMed]

51. De Cesco, S.; Kurian, J.; Dufresne, C.; Mittermaier, A.K.; Moitessier, N. Covalent inhibitors design and discovery. Eur. J. Med. Chem. 2017, 138, 96-114. [CrossRef]

52. Gehringer, M. Covalent inhibitors: Back on track? Future Med. Chem. 2020, 12, 1363-1368. [CrossRef]

53. Ghosh, A.K.; Samanta, I.; Mondal, A.; Liu, W.R. Covalent Inhibition in Drug Discovery. ChemMedChem 2019, 14, 889-906. [CrossRef]

54. Huber, E.M.; Groll, M. Inhibitors for the immuno- and constitutive proteasome: Current and future trends in drug development. Angew. Chem. Int. Ed. Engl. 2012, 51, 8708-8720. [CrossRef]

55. Arastu-Kapur, S.; Anderl, J.L.; Kraus, M.; Parlati, F.; Shenk, K.D.; Lee, S.J.; Muchamuel, T.; Bennett, M.K.; Driessen, C.; Ball, A.J.; et al. Nonproteasomal targets of the proteasome inhibitors bortezomib and carfilzomib: A link to clinical adverse events. Clin. Cancer Res. 2011, 17, 2734-2743. [CrossRef]

56. Chauhan, D.; Tian, Z.; Zhou, B.; Kuhn, D.; Orlowski, R.; Raje, N.; Richardson, P.; Anderson, K.C. In vitro and in vivo selective antitumor activity of a novel orally bioavailable proteasome inhibitor MLN9708 against multiple myeloma cells. Clin. Cancer Res. 2011, 17, 5311-5321. [CrossRef] [PubMed]

57. Pekol, T.; Daniels, J.S.; Labutti, J.; Parsons, I.; Nix, D.; Baronas, E.; Hsieh, F.; Gan, L.S.; Miwa, G. Human metabolism of the proteasome inhibitor bortezomib: Identification of circulating metabolites. Drug Metab. Dispos. 2005, 33, 771-777. [CrossRef] [PubMed]

58. Li, A.C.; Yu, E.; Ring, S.C.; Chovan, J.P. Boronic acid-containing proteasome inhibitors: Alert to potential pharmaceutical bioactivation. Chem. Res. Toxicol. 2013, 26, 608-615. [CrossRef]

59. Meng, L.; Mohan, R.; Kwok, B.H.; Elofsson, M.; Sin, N.; Crews, C.M. Epoxomicin, a potent and selective proteasome inhibitor, exhibits in vivo antiinflammatory activity. Proc. Natl. Acad. Sci. USA 1999, 96, 10403-10408. [CrossRef] [PubMed]

60. Groll, M.; Kim, K.B.; Kairies, N.; Huber, R.; Crews, C.M. Crystal structure of epoxomicin: $20 \mathrm{~S}$ proteasome reveals a molecular basis for selectivity of $\alpha^{\prime}, \beta^{\prime}$-epoxyketone proteasome inhibitors. J. Am. Chem. Soc. 2000, 122, 1237-1238. [CrossRef]

61. Herndon, T.M.; Deisseroth, A.; Kaminskas, E.; Kane, R.C.; Koti, K.M.; Rothmann, M.D.; Habtemariam, B.; Bullock, J.; Bray, J.D.; Hawes, J.; et al. U.S. Food and Drug Administration approval: Carfilzomib for the treatment of multiple myeloma. Clin. Cancer Res. 2013, 19, 4559-4563. [CrossRef]

62. Painuly, U.; Kumar, S. Efficacy of bortezomib as first-line treatment for patients with multiple myeloma. Clin. Med. Insights Oncol. 2013, 7, 53-73. [CrossRef]

63. Muchamuel, T.; Basler, M.; Aujay, M.A.; Suzuki, E.; Kalim, K.W.; Lauer, C.; Sylvain, C.; Ring, E.R.; Shields, J.; Jiang, J.; et al. A selective inhibitor of the immunoproteasome subunit LMP7 blocks cytokine production and attenuates progression of experimental arthritis. Nat. Med. 2009, 15, 781-787. [CrossRef]

64. Santos, R.L.A.; Bai, L.; Singh, P.K.; Murakami, N.; Fan, H.; Zhan, W.; Zhu, Y.; Jiang, X.; Zhang, K.; Assker, J.P.; et al. Structure of human immunoproteasome with a reversible and noncompetitive inhibitor that selectively inhibits activated lymphocytes. Nat. Commun. 2017, 8, 1692. [CrossRef]

65. Ladi, E.; Everett, C.; Stivala, C.E.; Daniels, B.E.; Durk, M.R.; Harris, S.F.; Huestis, M.P.; Purkey, H.E.; Staben, S.T.; Augustin, M.; et al. Design and Evaluation of Highly Selective Human Immunoproteasome Inhibitors Reveal a Compensatory Process That Preserves Immune Cell Viability. J. Med. Chem. 2019, 62, 7032-7041. [CrossRef]

66. Sanderson, M.P.; Friese-Hamim, M.; Walter-Bausch, G.; Busch, M.; Gaus, S.; Musil, D.; Rohdich, F.; Zanelli, U.; DowneyKopyscinski, S.L.; Mitsiades, C.S.; et al. M3258 is a selective inhibitor of the immunoproteasome subunit LMP7 (beta5i) delivering efficacy in multiple myeloma models. Mol. Cancer Ther. 2021. [CrossRef]

67. Hewings, D.S.; Flygare, J.A.; Wertz, I.E.; Bogyo, M. Activity-based probes for the multicatalytic proteasome. FEBS J. 2017, 284, 1540-1554. [CrossRef]

68. Basler, M.; Groettrup, M. Testing the Impact of Protease Inhibitors in Antigen Presentation Assays. Methods Mol. Biol. 2019, 1988, 59-69. [CrossRef]

69. Basler, M.; Lindstrom, M.M.; LaStant, J.J.; Bradshaw, J.M.; Owens, T.D.; Schmidt, C.; Maurits, E.; Tsu, C.; Overkleeft, H.S.; Kirk, C.J.; et al. Co-inhibition of immunoproteasome subunits LMP2 and LMP7 is required to block autoimmunity. EMBO Rep. 2018, 19, e46512. [CrossRef]

70. Gaczynska, M.; Rock, K.L.; Spies, T.; Goldberg, A.L. Peptidase activities of proteasomes are differentially regulated by the major histocompatibility complex-encoded genes for LMP2 and LMP7. Proc. Natl. Acad. Sci. USA 1994, 91, 9213-9217. [CrossRef] 
71. Ettari, R.; Cerchia, C.; Maiorana, S.; Guccione, M.; Novellino, E.; Bitto, A.; Grasso, S.; Lavecchia, A.; Zappala, M. Development of Novel Amides as Noncovalent Inhibitors of Immunoproteasomes. ChemMedChem 2019, 14, 842-852. [CrossRef]

72. Basler, M.; Lauer, C.; Moebius, J.; Weber, R.; Przybylski, M.; Kisselev, A.F.; Tsu, C.; Groettrup, M. Why the structure but not the activity of the immunoproteasome subunit low molecular mass polypeptide 2 rescues antigen presentation. J. Immunol. 2012, 189, 1868-1877. [CrossRef]

73. De Bruin, G.; Huber, E.M.; Xin, B.T.; van Rooden, E.J.; Al-Ayed, K.; Kim, K.B.; Kisselev, A.F.; Driessen, C.; van der Stelt, M.; van der Marel, G.A.; et al. Structure-based design of beta1i or beta5i specific inhibitors of human immunoproteasomes. J. Med. Chem. 2014, 57, 6197-6209. [CrossRef]

74. Ho, Y.K.; Bargagna-Mohan, P.; Wehenkel, M.; Mohan, R.; Kim, K.B. LMP2-specific inhibitors: Chemical genetic tools for proteasome biology. Chem. Biol. 2007, 14, 419-430. [CrossRef]

75. Bhattarai, D.; Lee, M.J.; Baek, A.; Yeo, I.J.; Miller, Z.; Baek, Y.M.; Lee, S.; Kim, D.E.; Hong, J.T.; Kim, K.B. LMP2 Inhibitors as a Potential Treatment for Alzheimer's Disease. J. Med. Chem. 2020, 63, 3763-3783. [CrossRef] [PubMed]

76. Johnson, H.W.B.; Anderl, J.L.; Bradley, E.K.; Bui, J.; Jones, J.; Arastu-Kapur, S.; Kelly, L.M.; Lowe, E.; Moebius, D.C.; Muchamuel, T.; et al. Discovery of Highly Selective Inhibitors of the Immunoproteasome Low Molecular Mass Polypeptide 2 (LMP2) Subunit. ACS Med. Chem. Lett. 2017, 8, 413-417. [CrossRef]

77. Xin, B.T.; Huber, E.M.; de Bruin, G.; Heinemeyer, W.; Maurits, E.; Espinal, C.; Du, Y.; Janssens, M.; Weyburne, E.S.; Kisselev, A.F.; et al. Structure-Based Design of Inhibitors Selective for Human Proteasome beta2c or beta2i Subunits. J. Med. Chem. 2019, 62, 1626-1642. [CrossRef] [PubMed]

78. Kasam, V.; Lee, N.R.; Kim, K.B.; Zhan, C.G. Selective immunoproteasome inhibitors with non-peptide scaffolds identified from structure-based virtual screening. Bioorg. Med. Chem. Lett. 2014, 24, 3614-3617. [CrossRef]

79. Sosic, I.; Gobec, M.; Brus, B.; Knez, D.; Zivec, M.; Konc, J.; Lesnik, S.; Ogrizek, M.; Obreza, A.; Zigon, D.; et al. Nonpeptidic Selective Inhibitors of the Chymotrypsin-Like (beta5 i) Subunit of the Immunoproteasome. Angew. Chem. Int. Ed. Engl. 2016, 55, 5745-5748. [CrossRef] [PubMed]

80. Sula Karreci, E.; Fan, H.; Uehara, M.; Mihali, A.B.; Singh, P.K.; Kurdi, A.T.; Solhjou, Z.; Riella, L.V.; Ghobrial, I.; Laragione, T.; et al. Brief treatment with a highly selective immunoproteasome inhibitor promotes long-term cardiac allograft acceptance in mice. Proc. Natl. Acad. Sci. USA 2016, 113, E8425-E8432. [CrossRef] [PubMed]

81. Alam, M.; Hawley, R.C.; Lynch, S.M.; Narayanan, A. Substituted Thiazole Compounds. WO 2014086701.A1, 12 June 2014.

82. Klein, M.; Schadt, O.; Haselmayer, P.; Krier, M. Boronic Acid Derivatives. WO2016050358.A1, 7 April 2016.

83. Dubiella, C.; Baur, R.; Cui, H.; Huber, E.M.; Groll, M. Selective Inhibition of the Immunoproteasome by Structure-Based Targeting of a Non-catalytic Cysteine. Angew. Chem. Int. Ed. Engl. 2015, 54, 15888-15891. [CrossRef] [PubMed]

84. Bosc, E.; Nastri, J.; Lefort, V.; Valli, M.; Contiguiba, F.; Pioli, R.; Furlan, M.; Bolzani, V.D.S.; El Amri, C.; Reboud-Ravaux, M. Piperlongumine and some of its analogs inhibit selectively the human immunoproteasome over the constitutive proteasome. Biochem. Biophys. Res. Commun. 2018, 496, 961-966. [CrossRef] [PubMed]

85. Scarpino, A.; Bajusz, D.; Proj, M.; Gobec, M.; Sosic, I.; Gobec, S.; Ferenczy, G.G.; Keseru, G.M. Discovery of Immunoproteasome Inhibitors Using Large-Scale Covalent Virtual Screening. Molecules 2019, 24. [CrossRef] [PubMed]

86. Parlati, F.; Lee, S.J.; Aujay, M.; Suzuki, E.; Levitsky, K.; Lorens, J.B.; Micklem, D.R.; Ruurs, P.; Sylvain, C.; Lu, Y.; et al. Carfilzomib can induce tumor cell death through selective inhibition of the chymotrypsin-like activity of the proteasome. Blood 2009, 114, 3439-3447. [CrossRef] [PubMed]

87. Johnson, H.W.B.; Lowe, E.; Anderl, J.L.; Fan, A.; Muchamuel, T.; Bowers, S.; Moebius, D.C.; Kirk, C.; McMinn, D.L. Required Immunoproteasome Subunit Inhibition Profile for Anti-Inflammatory Efficacy and Clinical Candidate KZR-616 ((2 S,3 R)- N-(( S)-3-(Cyclopent-1-en-1-yl)-1-(( R)-2-methyloxiran-2-yl)-1-oxopropan-2-yl)-3-hydroxy-3-(4-methoxyphenyl)-2-(( S)-2-(2morpholinoacetamido)propanamido)propenamide). J. Med. Chem. 2018, 61, 11127-11143. [CrossRef] [PubMed]

88. Ettari, R.; Pallio, G.; Pizzino, G.; Irrera, N.; Zappala, M.; Maiorana, S.; Di Chio, C.; Altavilla, D.; Squadrito, F.; Bitto, A. Noncovalent immunoproteasome inhibitors induce cell cycle arrest in multiple myeloma MM.1R cells. J. Enzyme Inhib. Med. Chem. 2019, 34, 1307-1313. [CrossRef]

89. Kuhn, D.J.; Hunsucker, S.A.; Chen, Q.; Voorhees, P.M.; Orlowski, M.; Orlowski, R.Z. Targeted inhibition of the immunoproteasome is a potent strategy against models of multiple myeloma that overcomes resistance to conventional drugs and nonspecific proteasome inhibitors. Blood 2009, 113, 4667-4676. [CrossRef]

90. Lynch, S.M.; Neidhart, W.; Plancher, J.-M.; Schulz-Gasch, T. Substituted Triazole Boronic Acid Compounds. WO2014086664, 12 June 2014.

91. Basler, M.; Maurits, E.; de Bruin, G.; Koerner, J.; Overkleeft, H.S.; Groettrup, M. Amelioration of autoimmunity with an inhibitor selectively targeting all active centres of the immunoproteasome. Br. J. Pharmacol. 2018, 175, 38-52. [CrossRef] [PubMed]

92. Olhava, E.J.; Danca, M.D. Proteasome Inhibitors. US7838673B2, 23 November 2010.

93. Du, S.H.; Xiang, Y.J.; Liu, L.; Nie, M.; Hou, Y.; Wang, L.; Li, B.B.; Xu, M.; Teng, Q.L.; Peng, J.; et al. Co-Inhibition of the Immunoproteasome Subunits LMP2 and LMP7 Ameliorates Immune Thrombocytopenia. Front. Immunol. 2021, $11,603278$. [CrossRef] [PubMed]

94. Kim, K.B.; Myung, J.; Sin, N.; Crews, C.M. Proteasome inhibition by the natural products epoxomicin and dihydroeponemycin: Insights into specificity and potency. Bioorg. Med. Chem. Lett. 1999, 9, 3335-3340. [CrossRef] 
95. Lei, B.; Abdul Hameed, M.D.; Hamza, A.; Wehenkel, M.; Muzyka, J.L.; Yao, X.J.; Kim, K.B.; Zhan, C.G. Molecular basis of the selectivity of the immunoproteasome catalytic subunit LMP2-specific inhibitor revealed by molecular modeling and dynamics simulations. J. Phys. Chem. B 2010, 114, 12333-12339. [CrossRef] [PubMed]

96. Meng, L.; Kwok, B.H.; Sin, N.; Crews, C.M. Eponemycin exerts its antitumor effect through the inhibition of proteasome function. Cancer Res. 1999, 59, 2798-2801.

97. Wehenkel, M.; Ban, J.O.; Ho, Y.K.; Carmony, K.C.; Hong, J.T.; Kim, K.B. A selective inhibitor of the immunoproteasome subunit LMP2 induces apoptosis in PC-3 cells and suppresses tumour growth in nude mice. Br. J. Cancer 2012, 107, 53-62. [CrossRef] [PubMed]

98. Wehenkel, M.V. Target validation of UK-101 and Functional Studies of $\beta 1$ i. 2011. Available online: https://uknowledge.uky.edu/ pharmacy_etds / 2 (accessed on 28 July 2021).

99. Britton, M.; Lucas, M.M.; Downey, S.L.; Screen, M.; Pletnev, A.A.; Verdoes, M.; Tokhunts, R.A.; Amir, O.; Goddard, A.L.; Pelphrey, P.M.; et al. Selective Inhibitor of Proteasome's Caspase-like Sites Sensitizes Cells to Specific Inhibition of Chymotrypsin-like Sites. Chem. Biol. 2009, 16, 1278-1289. [CrossRef]

100. Blackburn, C.; Gigstad, K.M.; Hales, P.; Garcia, K.; Jones, M.; Bruzzese, F.J.; Barrett, C.; Liu, J.X.; Soucy, T.A.; Sappal, D.S.; et al. Characterization of a new series of non-covalent proteasome inhibitors with exquisite potency and selectivity for the $20 \mathrm{~S}$ beta5-subunit. Biochem. J. 2010, 430, 461-476. [CrossRef] [PubMed]

101. Huber, E.M.; de Bruin, G.; Heinemeyer, W.; Paniagua Soriano, G.; Overkleeft, H.S.; Groll, M. Systematic Analyses of Substrate Preferences of $20 S$ Proteasomes Using Peptidic Epoxyketone Inhibitors. J. Am. Chem. Soc. 2015, 137, 7835-7842. [CrossRef] [PubMed]

102. Schiffrer, E.S.; Sosic, I.; Sterman, A.; Mravljak, J.; Rascan, I.M.; Gobec, S.; Gobec, M. A focused structure-activity relationship study of psoralen-based immunoproteasome inhibitors. MedChem Comm 2019, 10, 1958-1965. [CrossRef] [PubMed]

103. Singh, P.K.; Fan, H.; Jiang, X.; Shi, L.; Nathan, C.F.; Lin, G. Immunoproteasome beta5i-Selective Dipeptidomimetic Inhibitors. ChemMedChem 2016, 11, 2127-2131. [CrossRef]

104. Zhan, W.; Singh, P.K.; Ban, Y.; Qing, X.; Ah Kioon, M.D.; Fan, H.; Zhao, Q.; Wang, R.; Sukenick, G.; Salmon, J.; et al. StructureActivity Relationships of Noncovalent Immunoproteasome beta5i-Selective Dipeptides. J. Med. Chem. 2020, 63, 13103-13123. [CrossRef] [PubMed]

105. Cui, H.; Baur, R.; Le Chapelain, C.; Dubiella, C.; Heinemeyer, W.; Huber, E.M.; Groll, M. Structural Elucidation of a Nonpeptidic Inhibitor Specific for the Human Immunoproteasome. Chembiochem. 2017, 18, 523-526. [CrossRef]

106. Huber, E.M.; Heinemeyer, W.; de Bruin, G.; Overkleeft, H.S.; Groll, M. A humanized yeast proteasome identifies unique binding modes of inhibitors for the immunosubunit beta5i. EMBO J. 2016, 35, 2602-2613. [CrossRef]

107. Gallastegui, N.; Beck, P.; Arciniega, M.; Huber, R.; Hillebrand, S.; Groll, M. Hydroxyureas as noncovalent proteasome inhibitors. Angew. Chem. Int. Ed. Engl. 2012, 51, 247-249. [CrossRef] [PubMed]

108. Serafimova, I.M.; Pufall, M.A.; Krishnan, S.; Duda, K.; Cohen, M.S.; Maglathlin, R.L.; McFarland, J.M.; Miller, R.M.; Frodin, M.; Taunton, J. Reversible targeting of noncatalytic cysteines with chemically tuned electrophiles. Nat. Chem. Biol. 2012, 8, 471-476. [CrossRef] [PubMed]

109. Loidl, G.; Groll, M.; Musiol, H.J.; Ditzel, L.; Huber, R.; Moroder, L. Bifunctional inhibitors of the trypsin-like activity of eukaryotic proteasomes. Chem. Biol. 1999, 6, 197-204. [CrossRef]

110. Owens, T.; Brameld, K. LMP7 Inhibitors. WO2015195950.A1, 23 December 2015.

111. Quesne, M.G.; Ward, R.A.; de Visser, S.P. Cysteine protease inhibition by nitrile-based inhibitors: A computational study. Front. Chem. 2013, 1, 39. [CrossRef] [PubMed]

112. Groll, M.; Schellenberg, B.; Bachmann, A.S.; Archer, C.R.; Huber, R.; Powell, T.K.; Lindow, S.; Kaiser, M.; Dudler, R. A plant pathogen virulence factor inhibits the eukaryotic proteasome by a novel mechanism. Nature 2008, 452, 755-758. [CrossRef]

113. Tripathi, S.K.; Biswal, B.K. Piperlongumine, a potent anticancer phytotherapeutic: Perspectives on contemporary status and future possibilities as an anticancer agent. Pharmacol. Res. 2020, 156, 104772. [CrossRef]

114. Klein, M.; Busch, M.; Esdar, C.; Friese-Hamim, M.; Krier, M.; Musil, D.; Rohdich, F.; Sanderson, M.; Walter, G.; Schadt, O.; et al Abstract LB-054: Discovery and profiling of M3258, a potent and selective LMP7 inhibitor demonstrating high efficacy in multiple myeloma models. Cancer Res. 2019, 79, LB-054. [CrossRef]

115. Klein, M.; Busch, M.; Friese-Hamim, M.; Crosignani, S.; Fuchss, T.; Musil, D.; Rohdich, F.; Sanderson, M.P.; Seenisamy, J.; Walter-Bausch, G.; et al. Structure-Based Optimization and Discovery of M3258, a Specific Inhibitor of the Immunoproteasome Subunit LMP7 (beta5i). J. Med. Chem. 2021. [CrossRef] [PubMed]

116. Sanderson, M.; Busch, M.; Esdar, C.; Friese-Hamim, M.; Krier, M.; Ma, J.; Musil, D.; Rohdich, F.; Sloot, W.; Walter, G.; et al. Abstract DDT02-01: First-time disclosure of M3258: A selective inhibitor of the immunoproteasome subunit LMP7 with potential for improved therapeutic utility in multiple myeloma compared to pan-proteasome inhibitors. Cancer Res. 2019, 79, DDT02-01. [CrossRef]

117. Singh, A.V.; Bandi, M.; Aujay, M.A.; Kirk, C.J.; Hark, D.E.; Raje, N.; Chauhan, D.; Anderson, K.C. PR-924, a selective inhibitor of the immunoproteasome subunit LMP-7, blocks multiple myeloma cell growth both in vitro and in vivo. Br. J. Haematol. 2011, 152, 155-163. [CrossRef] [PubMed] 
118. Niewerth, D.; van Meerloo, J.; Jansen, G.; Assaraf, Y.G.; Hendrickx, T.C.; Kirk, C.J.; Anderl, J.L.; Zweegman, S.; Kaspers, G.J.; Cloos, J. Anti-leukemic activity and mechanisms underlying resistance to the novel immunoproteasome inhibitor PR-924. Biochem. Pharmacol. 2014, 89, 43-51. [CrossRef] [PubMed]

119. Sharma, L.K.; Lee, N.R.; Jang, E.R.; Lei, B.; Zhan, C.G.; Lee, W.; Kim, K.B. Activity-based near-infrared fluorescent probe for LMP7: A chemical proteomics tool for the immunoproteasome in living cells. Chembiochem 2012, 13, 1899-1903. [CrossRef]

120. Smith, B.C.; Sinyuk, M.; Jenkins, J.E., 3rd; Psenicka, M.W.; Williams, J.L. The impact of regional astrocyte interferon-gamma signaling during chronic autoimmunity: A novel role for the immunoproteasome. J. Neuroinflamm. 2020, 17, 184. [CrossRef]

121. Thompson, R.C. Peptide aldehydes: Potent inhibitors of serine and cysteine proteases. Methods Enzymol. 1977, 46, 220-225. [CrossRef] [PubMed]

122. Basler, M.; Claus, M.; Klawitter, M.; Goebel, H.; Groettrup, M. Immunoproteasome Inhibition Selectively Kills Human CD14(+) Monocytes and as a Result Dampens IL-23 Secretion. J. Immunol. 2019, 203, 1776-1785. [CrossRef] [PubMed]

123. Basler, M.; Dajee, M.; Moll, C.; Groettrup, M.; Kirk, C.J. Prevention of experimental colitis by a selective inhibitor of the immunoproteasome. J. Immunol. 2010, 185, 634-641. [CrossRef]

124. Liu, R.T.; Zhang, P.; Yang, C.L.; Pang, Y.; Zhang, M.; Zhang, N.; Yue, L.T.; Li, X.L.; Li, H.; Duan, R.S. ONX-0914, a selective inhibitor of immunoproteasome, ameliorates experimental autoimmune myasthenia gravis by modulating humoral response. $J$. Neuroimmunol. 2017, 311, 71-78. [CrossRef]

125. Nagayama, Y.; Nakahara, M.; Shimamura, M.; Horie, I.; Arima, K.; Abiru, N. Prophylactic and therapeutic efficacies of a selective inhibitor of the immunoproteasome for Hashimoto's thyroiditis, but not for Graves' hyperthyroidism, in mice. Clin. Exp. Immunol. 2012, 168, 268-273. [CrossRef] [PubMed]

126. Ichikawa, H.T.; Conley, T.; Muchamuel, T.; Jiang, J.; Lee, S.; Owen, T.; Barnard, J.; Nevarez, S.; Goldman, B.I.; Kirk, C.J.; et al. Beneficial effect of novel proteasome inhibitors in murine lupus via dual inhibition of type I interferon and autoantibody-secreting cells. Arthritis Rheum. 2012, 64, 493-503. [CrossRef]

127. Liu, H.; Wan, C.; Ding, Y.; Han, R.; He, Y.; Xiao, J.; Hao, J. PR-957, a selective inhibitor of immunoproteasome subunit low-MW polypeptide 7, attenuates experimental autoimmune neuritis by suppressing Th17-cell differentiation and regulating cytokine production. FASEB J. 2017, 31, 1756-1766. [CrossRef] [PubMed]

128. Bockstahler, M.; Fischer, A.; Goetzke, C.C.; Neumaier, H.L.; Sauter, M.; Kespohl, M.; Muller, A.M.; Meckes, C.; Salbach, C.; Schenk, M.; et al. Heart-Specific Immune Responses in an Animal Model of Autoimmune-Related Myocarditis Mitigated by an Immunoproteasome Inhibitor and Genetic Ablation. Circulation 2020, 141, 1885-1902. [CrossRef]

129. Basler, M.; Mundt, S.; Muchamuel, T.; Moll, C.; Jiang, J.; Groettrup, M.; Kirk, C.J. Inhibition of the immunoproteasome ameliorates experimental autoimmune encephalomyelitis. EMBO Mol. Med. 2014, 6, 226-238. [CrossRef] [PubMed]

130. Li, J.; Basler, M.; Alvarez, G.; Brunner, T.; Kirk, C.J.; Groettrup, M. Immunoproteasome inhibition prevents chronic antibodymediated allograft rejection in renal transplantation. Kidney Int. 2018, 93, 670-680. [CrossRef]

131. Zilberberg, J.; Matos, J.; Dziopa, E.; Dziopa, L.; Yang, Z.; Kirk, C.J.; Assefnia, S.; Korngold, R. Inhibition of the Immunoproteasome Subunit LMP7 with ONX 0914 Ameliorates Graft-versus-Host Disease in an MHC-Matched Minor Histocompatibility AntigenDisparate Murine Model. Biol. Blood Marrow Transplant. 2015, 21, 1555-1564. [CrossRef]

132. Althof, N.; Goetzke, C.C.; Kespohl, M.; Voss, K.; Heuser, A.; Pinkert, S.; Kaya, Z.; Klingel, K.; Beling, A. The immunoproteasomespecific inhibitor ONX 0914 reverses susceptibility to acute viral myocarditis. EMBO Mol. Med. 2018, 10, 200-218. [CrossRef]

133. Von Brzezinski, L.; Saring, P.; Landgraf, P.; Cammann, C.; Seifert, U.; Dieterich, D.C. Low Neurotoxicity of ONX-0914 Supports the Idea of Specific Immunoproteasome Inhibition as a Side-Effect-Limiting, Therapeutic Strategy. Eur. J. Microbiol. Immunol. 2017, 7, 234-245. [CrossRef] [PubMed]

134. Del Rio Oliva, M.; Basler, M.; Bomba, D.; Lam, D.; Brandl, J.; Kirk, C.; Groettrup, M. KZR-616, a first-in-class selective inhibitor of the immunoproteasome, ameliorates polymyositis in a murine model. In Proceedings of the ACR Convergence 2020, Online, 5-9 November 2020; p. 72.

135. Muchamuel, T.; Anderl, J.L.; Fan, R.A.; Johnson, H.W.B.; Kirk, C.J.; Lowe, E. KZR-616, a selective inhibitor of the immunoproteasome, blocks the disease progression in multiple models of systemic lupus erythematosus (SLE). Ann. Rheum. Dis. 2018. [CrossRef]

136. Zerfas, B.L.; Maresh, M.E.; Trader, D.J. The Immunoproteasome: An Emerging Target in Cancer and Autoimmune and Neurological Disorders. J. Med. Chem. 2020, 63, 1841-1858. [CrossRef] [PubMed]

137. Lickliter, J.; Bomba, D.; Anderl, J.; Fan, A.; Kirk, C.J.; Wang, J. AB0509 KZR-616, a selective inhibitor of the immunoproteasome, shows a promising safety and target inhibition profile in a phase i, double-blind, single (SAD) and multiple ascending dose (MAD) study in healthy volunteers. Ann. Rheum. Dis. 2018, 77, 1413-1414. [CrossRef]

138. Sherman, D.J.; Li, J. Proteasome Inhibitors: Harnessing Proteostasis to Combat Disease. Molecules 2020, 25, 671. [CrossRef] [PubMed] 